\title{
Modelling soil moisture in a high-latitude landscape using LiDAR and soil data
}

Kemppinen, Julia

2018-04

Kemppinen, J , Niittynen , P , Riihimaki , H \& Luoto , M 2018 , ' Modelling soil moisture in a high-latitude landscape using LiDAR and soil data ' , Earth Surface Processes and Landforms , vol. 43 , no. 5 , pp. 1019-1031 . https://doi.org/10.1002/esp.4301

http://hdl.handle.net/10138/313172

https://doi.org/10.1002/esp.4301

unspecified

acceptedVersion

Downloaded from Helda, University of Helsinki institutional repository.

This is an electronic reprint of the original article.

This reprint may differ from the original in pagination and typographic detail.

Please cite the original version. 


\title{
Modelling soil moisture in a high-latitude landscapeusing LiDAR and soil data
}

\author{
Julia Kemppinen', Pekka Niittynen"1, Henri Riihimäki', Miska Luoto
}

1 University of Helsinki, Helsinki, Finland

\begin{abstract}
Soil moisture has a pronounced effect on Earth surface processes. Global soil moisture is strongly driven by climate, whereas at finer scales, the role of non-climatic drivers becomes more important. We provide insights into the significance of soil and land surface properties in landscape-scale soil moisture variation by utilising high-resolution Light Detection and Ranging data (LiDAR) and extensive field investigations. The data consist of 1200 study plots located in a high-latitude landscape of mountain tundra in north-western Finland. We measured the plots three times during growing season 2016 with a hand-held time-domain reflectometry sensor. To model soil moisture and its temporal variation, we used four statistical modelling methods: generalized linear models, generalized additive models, boosted regression trees, and random forests. The model fit of the soil moisture models were $\mathrm{R}^{2}=0.60$ and RMSE $8.04 \mathrm{VWC} \%$ on average, while the temporal variation models showed a lower fit of $\mathrm{R}^{2}=0.25$ and RMSE $13.11 \mathrm{CV} \%$. The predictive performances for the former were $\mathrm{R}^{2}$ $=0.47$ and RMSE 9.34 VWC\%, and for the latter $\mathrm{R}^{2}=0.01$ and RMSE $15.29 \mathrm{CV} \%$. Results were similar across the modelling methods, demonstrating a consistent pattern. Soil moisture and its temporal variation showed strong heterogeneity over short distances; therefore, soil moisture modelling benefits from high-resolution predictors, such as LiDAR based variables. In the soil moisture models, the strongest predictor was SAGA wetness index (SWI), based on a $1 \mathrm{~m}^{2}$ digital terrain model derived from LiDAR data, which outperformed soil predictors. Thus, our study supports the use of LiDAR based SWI in explaining fine-scale soil moisture variation. In the temporal variation models, the strongest predictor was the field-quantified organic layer depth variable. Our results show that spatial soil moisture predictions can be based on soil and land surface properties, yet the temporal models require further investigation.
\end{abstract}

Keywords: soil wetness, tundra, LiDAR, SAGA wetness index (SWI), spatial modelling

\section{Introduction}

Earth surface processes and landforms (Johnson and Sitar 1990, Jaesche et al. 2003, Hoover and Rogers 2016) and Earth-atmosphere interactions (Koster et al. 2004, Seneviratne et al. 2006, Jung et al. 2010) are profoundly impacted by soil moisture. Soil moisture plays a crucial role in water, energy, and biogeochemical cycles (Natali et al. 2015, Maxwell and Condon 2016, Tuttle and Salvucci 2016). In high-latitude landscapes, soil moisture is closely related to e.g., permafrost dynamics (Fisher et al. 2016), shrubification of the tundra (Ackerman et al. 2017), and increasing greenhouse gas emissions (Kwon et al. 2016). The importance of soil moisture research is magnified by rising temperatures in the Arctic (Serreze and Barry 2011, Xu et al. 2013, Winkler et al. 2016) that lead to earlier snowmelt and increased evaporation and further cause drought later in the snow-free period (Williams et al. 2009, Blankinship et al. 2014, Harpold and Molotch 2015). Soil moisture projections are further obscured by the substantial uncertainties and limitations concerning precipitation simulations (Huntington 2006, Bintanja and Andry 2017, Pfahl et al. 2017).

Soil moisture, unlike precipitation, can significantly vary over short distances (Engstrom et al. 2005, le Roux et al. 2013). Broad-scale soil moisture patterns are driven by climate (Seneviratne et al. 2010, Legates et al. 2011, McColl et al. 2017). However, at finer scales soil moisture variation is influenced by local soil and land surface properties as well (e.g., Grayson et al. 1997, Wilson and Gallant 2000,
Korres et al. 2015). Topography, such as slope angle and upslope ground-surface conditions, control the downslope flow of water (Beven and Kirkby 1979, Isard 1986, Crave and Gascuel-Odoux 1997). Soil properties, for example soil texture, regulate the amount of water percolating the soil (Cosby et al. 1984, Famiglietti et al. 1998, Teuling and Troch 2005). However, the importance of soil and land surface properties and their control over spatio-temporal variation of soil moisture has not been yet explicitly investigated in highlatitude landscapes.

The role of soil moisture is often underestimated in studies regarding high-latitude and high-alpine landscapes, due to the lack of data (Kammer et al. 2013, le Roux et al. 2013, Myers-Smith et al. 2015). Spatially extensive soil moisture measurements are challenging, since they are timeconsuming, expensive, and hard to obtain (Famiglietti et al. 2008, Hajek et al. 2013). Thus, terrain-based surrogates, such as wetness indices, are commonly used in the absence of field-obtained soil moisture data. Wetness indices describe the topographic control over the steady state of soil moisture and its spatial variation (Murphy et al. 2009, Southee et al. 2012, Buchanan et al. 2014). Therefore, other factors (e.g., precipitation events, hydrological seasons, and soil conditions) can cause variance between measured soil moisture values and wetness index values (Western et al. 2002). Wetness indices portray general soil moisture patterns, especially in deeper soils (Western et al. 2002, Murphy et al. 2011, Southee et al. 
2012). Whereas, at finer scales and in shallow soils, wetness indices may encounter challenges (Penna et al. 2009, le Roux et al. 2013, Ågren et al. 2014). This is due to the fact that often indices are based on low-quality terrain data that portray relatively poorly or ignore completely 1 ) local topography, such as minor flow channels and depressions (Sørensen and Seibert 2007, Ågren et al. 2014), and 2) variation in soil factors, for example soil texture, permeability, and soil depth (Jutras and Arp 2011, Oltean et al. 2016).

Soil moisture research benefits significantly from LiDAR (Light Detection And Ranging) technology (e.g., Sørensen and Seibert 2007, Murphy et al. 2009), which enables highresolution terrain mapping (Wehr and Lohr 1999). Rapidly evolving LiDAR is widely available and has recently become an essential remote sensing tool commonly used for developing more accurate wetness indices (Jaboyedoff et al. 2012). Compared to coarse-resolution topographic data, LiDAR is superior, as it has the capacity to provide terrain information at very fine-resolutions (Sørensen and Seibert 2007, Southee et al. 2012, Leempoel et al. 2015). However, few studies have utilised LiDAR for topographic investigations in the Arctic (Sørensen et al. 2006) regardless of its great potential in complimenting field-obtained soil moisture data (Lookingbill and Urban 2004, Famiglietti et al. 2008). Furthermore, the benefits of remote sensing are notable in high-latitude and high-altitude regions, which are often inaccessible.

Temporal variation of soil moisture plays an essential role in land-atmosphere feedbacks (e.g., Tuttle and Salvucci 2016), vegetation and soil ecosystem dynamics (Sylvain et al. 2014, Trahan and Schubert 2016), geomorphological hazards (Jaesche et al. 2003), and the global carbon cycle (Falloon et al. 2011). In addition, global warming amplifies temporal variation of soil moisture by intensifying aridity and droughts (Dai 2011, 2013, Berg et al. 2016). In the high-latitudes, this is realised as increasing frequency of heat waves (Hauser et al. 2016), tundra fire susceptibility (Sitch et al. 2003), and the disappearance of waterbodies across the Arctic (Smith et al. 2005, Smol and Douglas 2007, Andresen and Lougheed 2015). Thus, there is a need for more research focused on temporal variation of soil moisture.

This is the first study utilising spatially extensive highresolution data to examine soil moisture variation in a highlatitude landscape. We conducted an intensive and systematic soil moisture investigation, with 1200 study plots across an environmentally heterogeneous study area in northwestern Finland. Therefore, this examination represents a powerful study system to scrutinise the importance of soil and topography in controlling spatio-temporal soil moisture variation. The aim of this study was 1) to quantify both spatial and temporal variation of soil moisture across a high-latitude landscape; 2) to examine the influence of soil and topography variables on soil moisture pattern and its temporal variation in a multivariate system; and 3) to evaluate the predictive performance of these variables to model soil moisture variation at fine spatial resolution.

\section{Study area}

The study area extended $3 \mathrm{~km}^{2}$ covering various environmental gradients between two mountain massifs, Mount Saana and Mount Jehkas, in north-western Finland (69 $03^{\circ} \mathrm{N} 20^{\circ} 51^{\prime} \mathrm{E}$; Figure 1). The relative elevation reaches nearly $250 \mathrm{~m}$, with the highest point located on the northern slope of Mount Saana (808 $\mathrm{m}$ a.s.1.). The massifs form the geological margin of the Finnish Caledonian area overlaying a Precambrian base (Lehtovaara 1995). An organic layer, with varying thickness
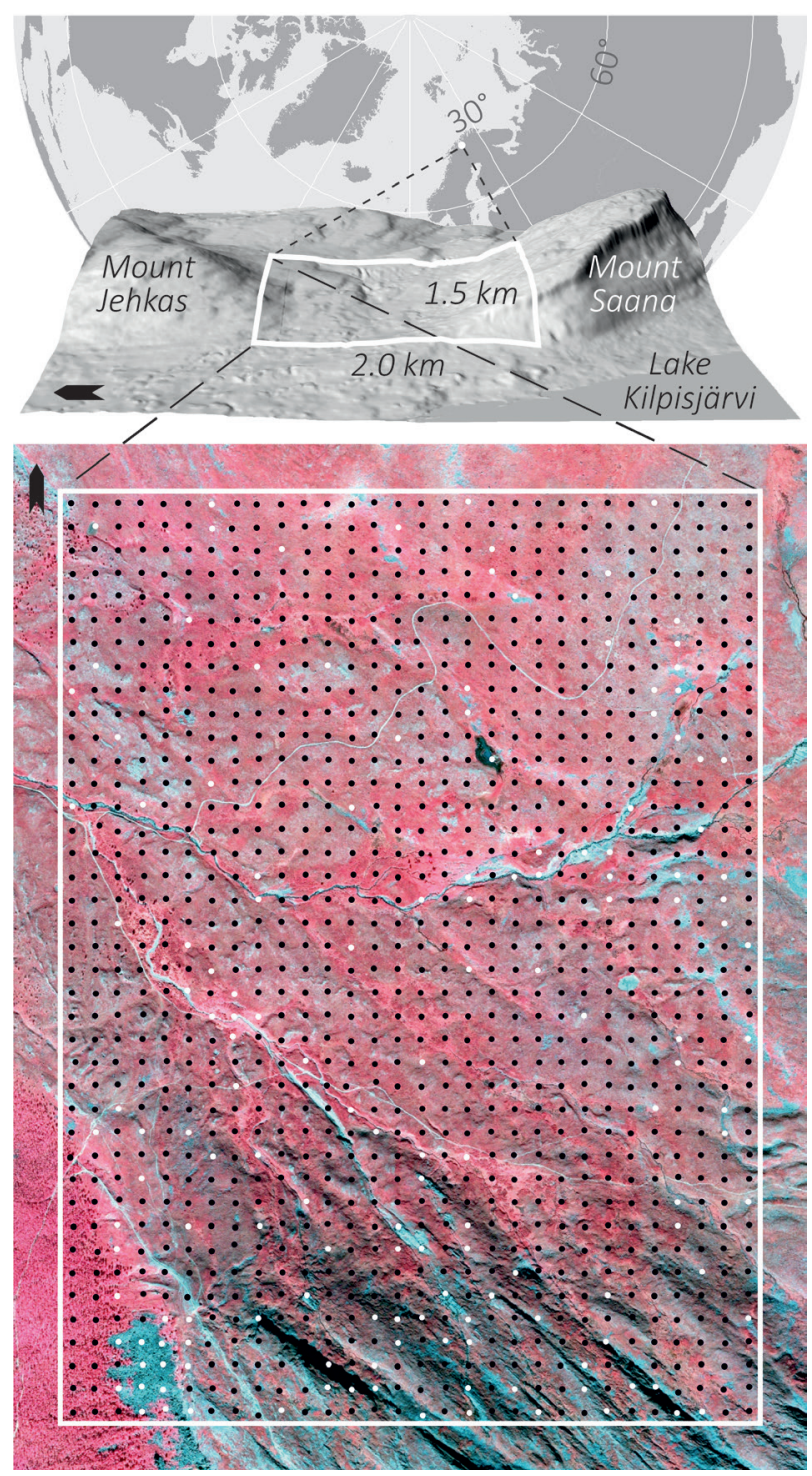

Figure 1. The study setting consists of 1200 plots, of which 1043 (black dots) were analysed. The white dots represent the remaining 157 plots, from which all three soil moisture measurements were not possible to obtain, due to snow cover or extremely shallow soils. Red indicates vegetation and blue rock surfaces in the false colour aerial image $(0.5$ $\mathrm{m}$ resolution), provided by the National Land Survey of Finland. This figure is available in colour at wileyonlinelibrary.com/journal/espl 
up to $70 \mathrm{~cm}$, covers nearly the whole area (Figure $7 \mathrm{C}$ ). The main vegetation type is dwarf-shrub dominated mountain heath. The treeline cuts through the south-western corner of the area with a mountain birch forest (Betula pubescens ssp. czerepanovii; ca. $650 \mathrm{~m}$ a.s.l.). The climate of the study area is affected by its high-latitude location in the Scandes Mountains and its close proximity to the Arctic Ocean (Aalto and Luoto 2014). July is the warmest and wettest month (June: $7.5^{\circ} \mathrm{C}$, $42 \mathrm{~mm}$; July: $11.2^{\circ} \mathrm{C}, 73 \mathrm{~mm}$; August: $9.6^{\circ} \mathrm{C}, 47 \mathrm{~mm}$; 1981 - 2010), measured at the nearby Kilpisjärvi meteorological station ( $1.5 \mathrm{~km}$ from the study area, $69^{\circ} 05^{\prime} \mathrm{N} 20^{\circ} 79^{\prime} \mathrm{E}$; 480 $\mathrm{m}$ a.s.1.) (Pirinen et al. 2012).

\section{Materials and methods}

\section{Soil moisture data}

Soil moisture data consisted of soil moisture and its temporal variation. The study setting consisted of 1200 study plots of $1 \mathrm{~m}^{2}$, systematically sampled at $50 \mathrm{~m}$ intervals (Figure 1). Soil moisture was measured on three moisture campaigns (June, July, and August 2016) each lasting three to five consecutive days (Figure 2). Soil moisture, measured as volumetric water content (VWC\%), was obtained with a handheld time-domain reflectometry sensor (FieldScout TDR 300; Spectrum Technologies Inc., Plainfield, IL, USA) up to a depth of $7.5 \mathrm{~cm}$, taking the mean of three measurements per plot during each campaign. We calibrated the devices using air and distilled water as advised by the manufacturer and verified that the devices showed similar soil moisture values with minimal variation (Spectrum Technologies 2012). Even though soil moisture measurements from different depths correlate strongly with each other (Tromp-van Meerveld and McDonnell 2006), only those plots with a soil depth $\geq$ $7.5 \mathrm{~cm}$ and that were snow free during all campaigns ( $\mathrm{n}=$ 1043) were further used in the analyses, as temporal variation throughout the campaign months could not be assessed with less than three measurements. All plots were marked in the field and their exact locations were recorded using a handheld GNSS receiver with accuracy up to $\leq 6 \mathrm{~cm}$ under optimal circumstances (GeoExplorer GeoXH 6000 Series; Trimble Inc., Sunnyvale, CA, USA).

Antecedent precipitation 48 hours prior to the first campaign was $0.6 \mathrm{~mm}$, the second $15.8 \mathrm{~mm}$, and the third $0.0 \mathrm{~mm}$ (Figure 2). Average precipitation sum during the first campaign was $0.2 \mathrm{~mm} / \mathrm{d}$, the second $2.6 \mathrm{~mm} / \mathrm{d}$, and the third $1.7 \mathrm{~mm} / \mathrm{d}$. To avoid possible bias in the data caused by rain events, we measured a calibration transect twice daily during the campaigns (Supplementary Material Appendix A). This transect was located in topographically varying terrain within the study area and thus had a representative soil moisture gradient. Temporal change at the transect was tested with

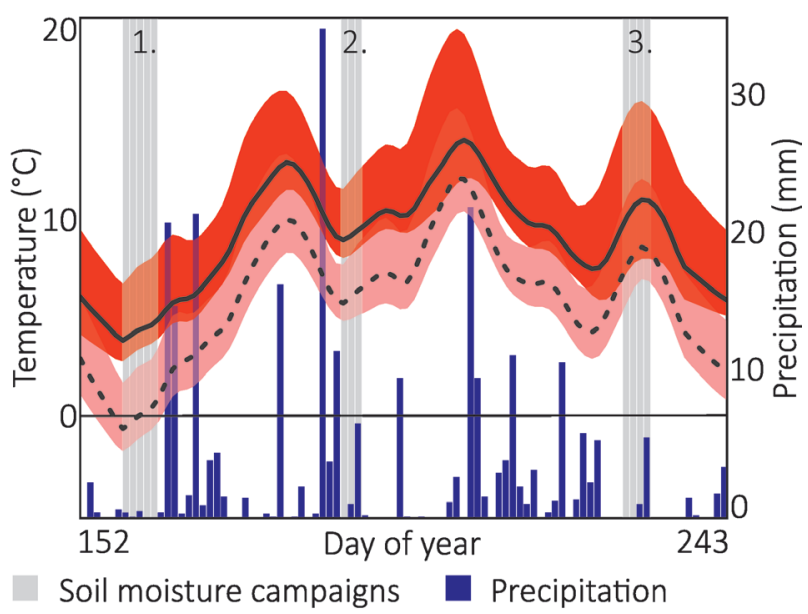

Saana station
$\because$ Mean temperature
$\quad$ Temperature range

Kilpisjärvi station

$\boldsymbol{u}$ Mean temperature

Temperature range

Figure 2. Temperature and precipitation during the soil moisture campaigns. The moisture campaigns were held on 158 - 162, $189-$ 191 , and $229-232$ day of year (DOY) in 2016. The study area was located near Kilpisjärvi meteorological station $(1.5 \mathrm{~km}$ from the study area, $480 \mathrm{~m}$ a.s.I) and Saana weather station $(2.0 \mathrm{~km}$ from the study area, $1002 \mathrm{~m}$ a.s.l.). The pillars represent total precipitation (snow and rain), which is only available for Kilpisjärvi meteorological station. Lines represent mean temperatures measured at both stations, and the shaded colouring represents their ranges. All weather data were derived from the database of the Finnish Meteorological Institute. This figure is available in colour at wileyonlinelibrary.com/journal/espl

ANOVA F-test, and was found statistically significant only for the first moisture campaign, yet the difference between observed and calibrated values was rather subtle, $0.5 \mathrm{VWC} \%$ on average (Supplementary Material Appendix B). Thus, for consistency and comparability between the campaigns, uncalibrated moisture values were used for all analyses. In our models, soil moisture was represented by the mean values of each plot measured on all three moisture campaigns. Temporal variation of soil moisture was represented by the coefficient of variation $(\mathrm{CV} \%)$, which indicates the volume of change relative to the soil moisture level, thus, it does not denote the direction of change (Brown 1998). In other words, CV\% indicates, whether an area is stable or prone to experience temporal variation in soil moisture. $\mathrm{CV} \%$ is based on the ratio of the standard deviation $(\sigma)$ to the mean (Equation 1) (Brown 1998):

$$
\mathrm{CV}=\sigma / \text { mean }
$$

\section{Predictor variables}

Six predictors commonly used in soil moisture research were obtained from each plot for modelling both response variables (Equation 2), soil moisture and its temporal variation (e.g., Crave and Gascuel-Odoux 1997, Penna et al. 2009, Williams et al. 2009): 
Response variable $=\quad$ Organic layer depth +

Surficial deposits +

Elevation+Radiation+

SAGA wetness index+

Topographic position index (2).

All predictor variables, excluding the point measured organic layer depth, were extracted for each plot from the raster layers using Spatial Analyst toolbox in ArcMap (Esri 2012).

\section{Soil data}

Soil composition controls water percolation (Cosby et al. 1984, Teuling and Troch 2005), hence, the amount of organic matter in soil has a strong positive correlation with soil moisture (Hudson 1994). We determined organic layer depth with a thin metal rod (method modified from Rose and Malanson 2012, Aalto et al. 2013). The organic layer depth was measured to the nearest centimetre for layers $<10 \mathrm{~cm}$, and for layers $>$ $10 \mathrm{~cm}$ the measurements were rounded to the nearest $5 \mathrm{~cm}$. For visualisation, point measured organic layer depth was interpolated using multivariate kriging method from gstat package in R (Figure 7C) (R Development Core Team 2016). In addition to organic matter, texture is another important soil property, which is closely related to soil moisture (Cosby et al. 1984). Thus, we composed a surficial deposits classification of the study area (Figure 7D) using field surveys and highresolution $(0.5 \mathrm{~m})$ aerial images provided by the National Land Survey of Finland (Figure 1). The surficial deposits classification represents the main soil textures of the area: peat deposits, fluvial deposits, glacial till, boulders, and rock outcrops (Figure 7D).

\section{Terrain data}

The LiDAR data were obtained from the National Land Survey of Finland. The scanning of the area was performed during the third campaign $(228-229$ DOY, 16th -17 th of August 2016) with a Leica ALS60 laser scanner. Flight altitude was $2950 \mathrm{~m}$ a.s.l. (c. $2200 \mathrm{~m}$ above ground), beam divergence $\left(1 / \mathrm{e}^{2}\right)$ was $0.22 \mathrm{mrad}$, and the maximum scan angle was $20^{\circ}$. Nominal pulse spacing in the study area was $1.3 \mathrm{~m}$. The data were processed from the point cloud into a $1 \mathrm{~m}$ resolution digital terrain model (DTM) consisting only of ground classified last echoes using las2dem tool from LAStools (Isenburg 2017).

Land surface parameters, namely elevation, potential incoming solar radiation (radiation), SAGA wetness index (SWI), and topographic position index (TPI), were derived from the DTM using RSAGA package in R (Brenning 2008, Conrad et al. 2015, R Development Core Team 2016). Elevation ( $\mathrm{m}$ a.s.l.) describes the basic topography of a site, and creates zonation followed by several other environmental gradients, such as temperature, which controls, e.g., soil formation, soil climate, and soil activity (Amundson et al. 1989, Trumbore et al. 1996, Dahlgren et al. 1997).

Slope aspect affects soil moisture, since radiation distributes unevenly on north and south facing slopes creating varying soil temperature conditions (Isard 1986, Dai et al. 2004, le Roux et al. 2013). Soil temperature has a strong negative correlation with soil moisture during snow-free period (Aalto et al. 2013). Radiation was integrated for the campaign months (June, July, and August). The shadow effect from obstructing topography was taken into account with a sky view factor option (Böhner and Antonic 2009). Sun positions were calculated for every fifth day, with a four-hour interval. For atmospheric transmittance, we used the lumped atmosphere option.

SWI was used as a proxy of soil water accumulation (Böhner and Selige 2006). SWI is a modification of the commonly used, topographic wetness index (TWI) (Beven and Kirkby 1979). SWI takes into account small differences in elevation values by using an iterative modification of the specific catchment area (SCA). The modified SCA depends on the neighbouring maximum values and a given suction parameter, t, which was set to 20 (Böhner and Selige 2006). Thus, compared to the traditional flow accumulation algorithms (e.g., Freeman 1991, Moore et al. 1993), SWI (Equation 3) should perform better in flat areas, as such areas may direct the flow into wrong directions, hence falsifying the flow accumulation (Böhner and Selige 2006). We used a hydrologically corrected DTM for calculating SWI(Wang and Liu 2006). The multiple flow direction algorithm was used for SCA calculation (Freeman 1991, Kopecký and Č́žzová 2010). Finally, SWI was calculated with the given formula (Böhner and Selige 2006):

$$
\begin{aligned}
& \mathrm{SCA}_{\mathrm{M}}=\mathrm{SCA}_{\max }(1 / 20)^{\beta \exp (20 \beta)} \\
& \quad \text { for } \mathrm{SCA}<\mathrm{SCA}_{\max }(1 / 20)^{\beta \exp (20 \beta)} \\
& \mathrm{SWI}=\ln \left(\mathrm{SCA}_{\mathrm{M}} / \tan (\beta)\right)
\end{aligned}
$$

where $\beta$ is the slope angle (Equation 3.1), SCA is the specific catchment area, SCAM the modified specific catchment area (Equation 3.2), and tan ( $\beta$ ) is the local slope (Zevenbergen and Thorne 1987).

TPI describes the relative topographic position of a site: it is based on the elevation difference between the site and the mean elevation within a given radius (Guisan et al. 1999, Wilson and Gallant 2000, Weiss 2001, Ågren et al. 2014). Thus, TPI defines the relative position of a location along a topographic gradient (ridge top, middle slope, or depression). We used a non-filled DTM for calculating TPI with a 30 $\mathrm{m}$ radii, thus it is more representative of local-scale moist depressions, which are ignored by SWI, as SWI was calculated using the filled DTM. Positive TPI values represent sites, 
which are located higher compared to their surroundings, and negative values represent lower surroundings. Values close to zero represent flat areas or continuous slopes.

Before selecting the predictor variables, we considered other relevant land surface parameters derived from the $1 \mathrm{~m}^{2}$ DTM based on LiDAR data. One of them was the traditional TWI formula with the non-modified SCA (Equation 4),

$$
\mathrm{TWI}=\ln (\mathrm{SCA} / \tan \beta)
$$

where $\tan (\beta)$ is the local slope, but it was outperformed by SWI (Supplementary Material Appendix F). Slope was considered as a predictor as well (following Mitášova and Mitáš 1993, Moore et al. 1993), but was not used, as it is a component of both radiation and SWI. TPI is a highly scale dependent variable (Weiss 2001). Therefore, we calculated TPI with three other radii at micro $(1 \mathrm{~m}, 5 \mathrm{~m})$ and landscape $(100 \mathrm{~m})$ scales, in addition to the local scale $(30 \mathrm{~m})$. We chose the TPI with $30 \mathrm{~m}$ radii, as it had the highest Spearman correlations with the response variables (Supplementary Material Appendix F). Using the same radii $(1,5,30$, and $100 \mathrm{~m})$, we calculated the elevation difference between a site and the minimum elevation within a given radius, commonly referred as relative elevation (method from Ashcroft and Gollan 2012). However, relative elevation had a correlation of -0.46 on the average with SWI (Supplementary Material Appendix F).

\section{Spatial modelling}

We used four multivariate statistical methods to model soil moisture and its temporal variation: generalized linear models (GLM), generalized additive models (GAM), boosted regression trees (BRT), and random forests (RF) (Hastie and Tibshirani 1987, Breiman 2001, Elith etal. 2008). The methods represent both regression (GLM and GAM) and regression tree -based machine learning (BRT and RF) methods. GLM is a non-parametric extension of linear regression models that allows the use of non-normally distributed response variables (Nelder and Wedderburn 1972). GAM is similar to GLM, yet it is a more flexible method, as it splits the regression lines into segments and uses local spline smoothing functions to track the nonlinearity in the relationships between the response and predictor variables (Hastie and Tibshirani 1987). The user appoints the maximum complexity of the smoothing function, which is then applied to each predictor separately. Thus, the user controls the rate of fitting. BRT and RF are regression tree -based machine learning methods. Characteristic to tree models, they automatically account for interaction effects between the predictor variables and they can model complex nonlinear relationships (Breiman 2001, Elith et al. 2008). BRT splits the data internally multiple times into training and evaluating data, and builds the trees recursively using the information from the previous ones to improve the accuracy of the current tree (Boosting) (Elith et al. 2008). BRT requests the user to specify the distribution of error of the response variable, in order to calculate the residuals correctly during the boosting. While, RF does not require any user-specified assumptions on the data. RF bootstraps the data numerous times (random sample with replacement), but it also samples the predictor variables as candidates at each split during the tree fitting (Breiman 2001). Finally, when all individual trees are fitted, the RF algorithm produces an ensemble of the trees by averaging the final prediction over the ones produced by multiple trees (Bagging).

These modelling methods are commonly used for analysing large data sets in environmental research (e.g., Franklin 2010), and are quite common in soil science (McBratney et al. 2003, Scull et al. 2003, Ali et al. 2015). GLM is widely used for modelling both field-obtained and remotely sensed soil moisture data (e.g., Lane 2002, Srivastava et al. 2013). Compared to GLM, GAM is not as common in soil science (McBratney et al. 2003, Scull et al. 2003). Yet, it has been found to be superior compared to GLM in modelling soil organic carbon (Odeh et al. 1997). BRT is commonly used in soil science, e.g., for mapping groundwater or composing soil classifications (McBratney et al. 2000, Naghibi et al. 2016). In recent years, RF has been a popular method in soil moisture modelling and related studies (e.g., Ahmad et al. 2010, Hedley et al. 2013, Ali et al. 2015). The use of RF has significantly improved predictions of various soil properties, such as soil organic carbon, $\mathrm{pH}$, texture, and nutrients (Hengl et al. 2015). In addition, an ensemble model (ENS) based on all four modelling methods was evaluated, using the median value of the four methods (method modified from Araújo and New 2007, Marmion et al. 2009). ENS showed similar results as the individual methods, therefore the ENS are made available only in the Supplementary Material Appendix E.

GLM was fitted to the data using functions from the stats package. GAM was fitted using the mgcv package, with maximum degrees of smoothing restricted to four (Wood 2011). BRT was fitted using the gbm package, with interaction depth set to three, learning rate to 0.001 , bagging fraction to 0.5 , and number of trees to 3000 (Ridgeway 2017). RF was fitted using the randomForest package, with number of trees set to 500 (Liaw and Wiener 2002). The response variables were non-normally distributed, thus, response variables were log-transformed before all subsequent analyses. Gaussian distribution was assumed for GLM, GAM, and BRT.

\section{Model validation}

Model fit and predictive performance were evaluated using cross-validation with 100 permutations. In the cross-validation a random sample of $70 \%$ was used for testing model fit, and predictive performance was tested with the remaining 30\%. Models were evaluated and compared using the coefficient 
of determination $\left(\mathrm{R}^{2}\right)$, root-mean-squared-error (RMSE), and Nash-Sutcliffe Efficiency (NSE) for measuring the relationship between the predicted and the observed values with 100 permutations. RMSE and NSE were calculated using hydroGOF package (Zambrano-Bigiarini 2017). The statistical significance of the differences was determined with paired two-tailed Wilcoxon signed rank test using stats package.

Variable importance is a useful measure of individual contribution of a predictor variable in a multivariate model (Breiman 2001). With variable importance, we investigated which of the predictor variables were relatively the most influential, i.e. which predictors controlled soil moisture and its temporal variation. Variable importance was calculated in a randomised procedure, one by one for each predictor variable. First, the model was fitted with a non-manipulated data set. Secondly, the model was used to make predictions 1) to the data set used in the model fitting, and 2) to a data set, in which a certain predictor variable is shuffled randomly. Finally, the variable importance of the shuffled predictor was calculated using Pearson correlation coefficient as followed (Equation 5):

Variable importance $=$

1-corr (Prediction Prediction )$(5)$.

Thus, the results settled between zero and one. If the shuffled predictor variable had a high contribution in the model, the two predictions should differ greatly, i.e. the variable importance value should be close to one, indicating high individual contribution of the predictor variable. In our analyses, regardless of the modelling method, variable importance was calculated in the exact same manner, thus, it is fully comparable between modelling methods (Thuiller et al. 2009). We calculated variable importance with 100 permutations for each of the modelling methods and for all predictors separately. On each permutation round, the data set was first bootstrapped (random sample with replacement), for a slightly different data set on each round.

Spatial autocorrelation was examined using Moran's correlogram for both raw data and model residuals (Supplementary Material Appendix C). Regarding soil moisture, plots close to each other $(<100 \mathrm{~m})$ were moderately spatially autocorrelated for model residuals, whereas greater distances showed no spatial autocorrelation. For temporal variation of soil moisture, spatial autocorrelation was nearly absent for both raw data and model residuals. Thus, we did not continue to further evaluate spatial autocorrelation (Supplementary Material Appendix C).

The relationships between numerical predictor variables were assessed and tested with Spearman correlation using the stats package (R Development Core Team 2016). Correlations between the factor variable (surficial deposits) and other predictor variables were assessed with polycor package, and statistical significances were tested with Kruskal-Wallis test (Fox 2015). The BRT based spatial predictions for soil moisture and its temporal variation were created with the raster package (Hijmans 2015). All analyses and models were carried out in R (R Development Core Team 2016).

\section{Results}

Mean soil moisture was $22.0 \mathrm{VWC} \%$, varying within the study area from 4.6 to 78.2 VWC\% (Figure 3; Supplementary Material Appendix D). The mean temporal variation of soil moisture was $25.0 \mathrm{CV} \%$, ranging from low $(1.3 \mathrm{CV} \%)$ to high variation (99.0 CV\%) during the campaign months. Spearman correlations between numerical predictor variables were $\leq$ $|0.39|$ (Figure 4). Polyserial correlations between the factor variable (surficial deposits) and other predictor variables were $\leq|0.54|$ (Figure 4). Spearman correlations between the three campaigns ranged from 0.62 to 0.67 and were all statistically significant $(\mathrm{p} \leq 0.001)$ (Supplementary Material Appendix F).

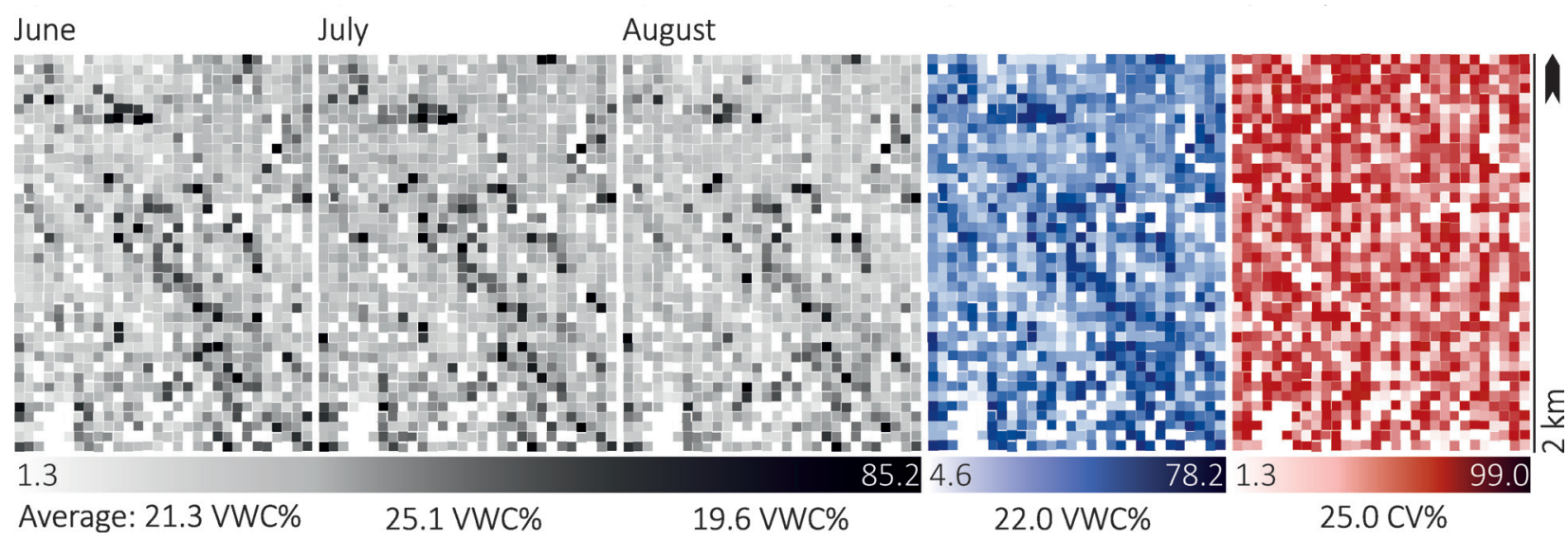

Figure 3. Spatial variation of soil moisture and its temporal variation. Soil moisture was investigated from 1200 plots during three moisture campaigns $(A-C)$. The campaign held on July was the wettest $(B)$, and August the driest (C). Soil moisture (D) and its temporal variation (E), i.e. the mean of the three measurements and the coefficient of variation (CV) respectively (Equation 1). The blank spaces represent the remaining 157 plots, from which measurements were not possible to obtain. This figure is available in colour at wileyonlinelibrary.com/journal/espl 


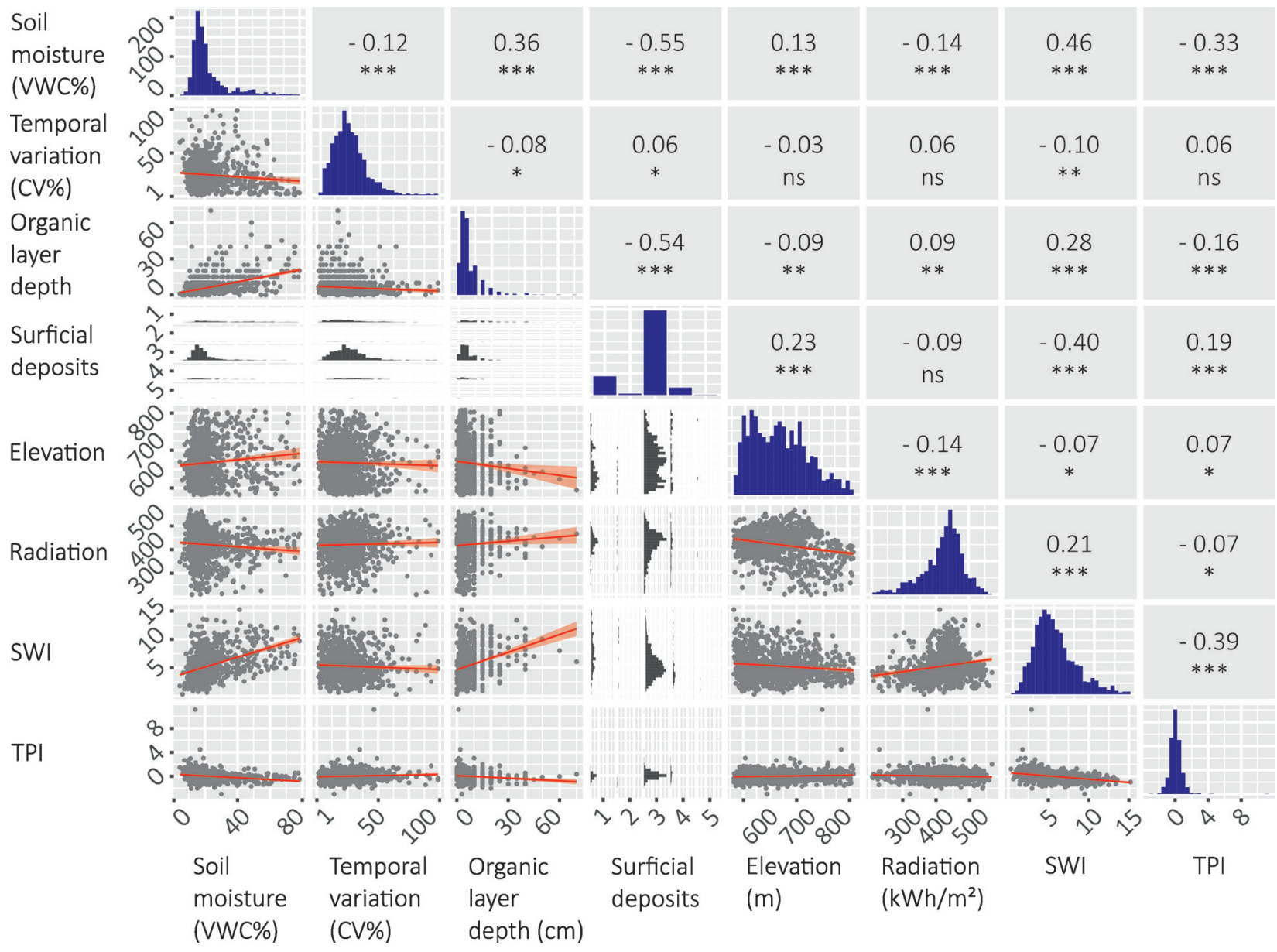

Figure 4. Relationships between variables. Spearman correlation was used to calculate the relationships between numerical variables, and polyserial correlation used for the factor variable (surficial elements) and other predictor variables. Statistical significance of the correlation: ${ }^{* * *}=p \leq 0.001$; ${ }^{* *}=p \leq 0.01 ;{ }^{*}=p \leq 0.05 ;$ ns = not significant. This figure is available in colour at wileyonlinelibrary.com/journal/espl

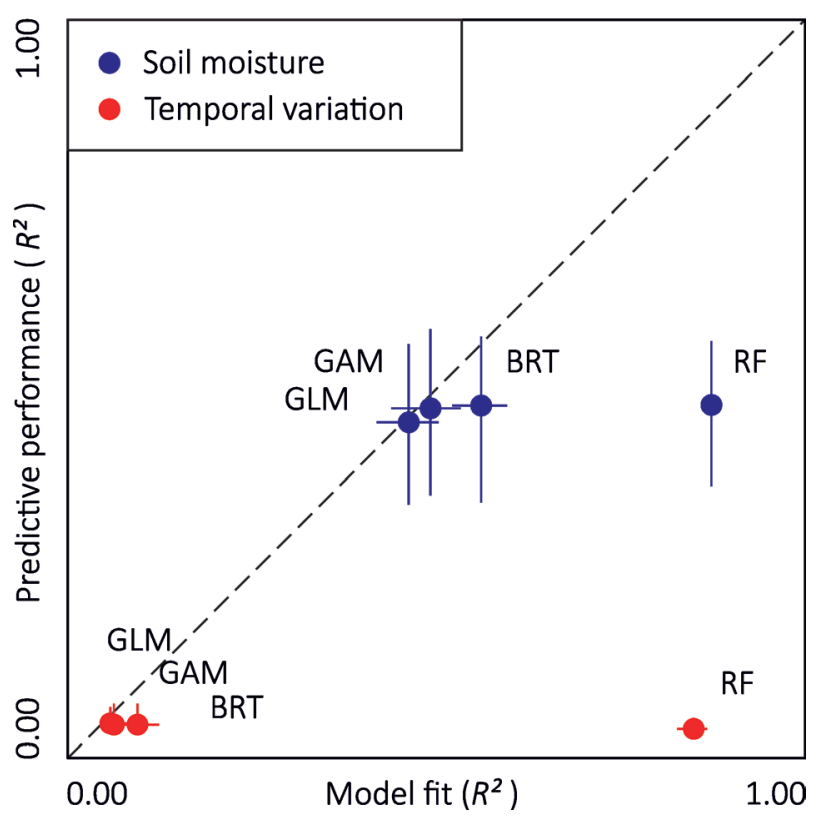

Figure 5. Comparing four soil moisture modelling methods. The predictive performance of the soil moisture models was moderate across methods, unlike temporal variation of soil moisture models, which performed poorly. The horizontal and vertical segments represent the ranges of each modelling method, which in some cases were minor, e.g., RF for temporal variation. This figure is available in colour at wileyonlinelibrary. com/journal/espl

All four modelling methods performed similarly when predicting soil moisture and its temporal variation (Figure
5; Supplementary Material Appendix E). They performed similarly, when modelling separately all three campaigns (Supplementary Material Appendix G). The average model fit of the soil moisture model was $\mathrm{R}^{2}=0.60$ and RMSE 8.04 $\mathrm{VWC} \%$, and for the temporal variation model $\mathrm{R}^{2}=0.25$ and RMSE 13.11 CV\% (100 permutations, four methods). Based on cross-validation, the average predictive performance of the soil moisture model was moderate: $\mathrm{R}^{2}=0.47$ and RMSE 9.34 $\mathrm{VWC} \%$, and for temporal variation model poor: $\mathrm{R}^{2}=0.01$ and RMSE 15.29 CV\%. The NSE values were similar to $\mathrm{R}^{2}$, therefore they are made available only in the Supplementary Material Appendix E.

SWI had a higher Spearman correlation with soil moisture compared to TWI $(0.46>0.18 ; p \leq 0.001)$ (Supplementary Material Appendix F). Spearman correlation between SWI and TWI was $0.50(\mathrm{p} \leq 0.001)$. The soil moisture models were mainly influenced by SWI, which was indicated by all four multivariate models (Figure 6A). Other important variables in the soil moisture models were soil properties: organic layer depth and surficial deposits. Organic layer depth had a positive correlation with soil moisture, showing a threshold type of response: increase of soil moisture levelled off after $\geq 30 \mathrm{~cm}$ deep layers (Figure 6B). The influence of organic matter was also highlighted by surficial deposits: peat deposits contained 
A) Soil Topography
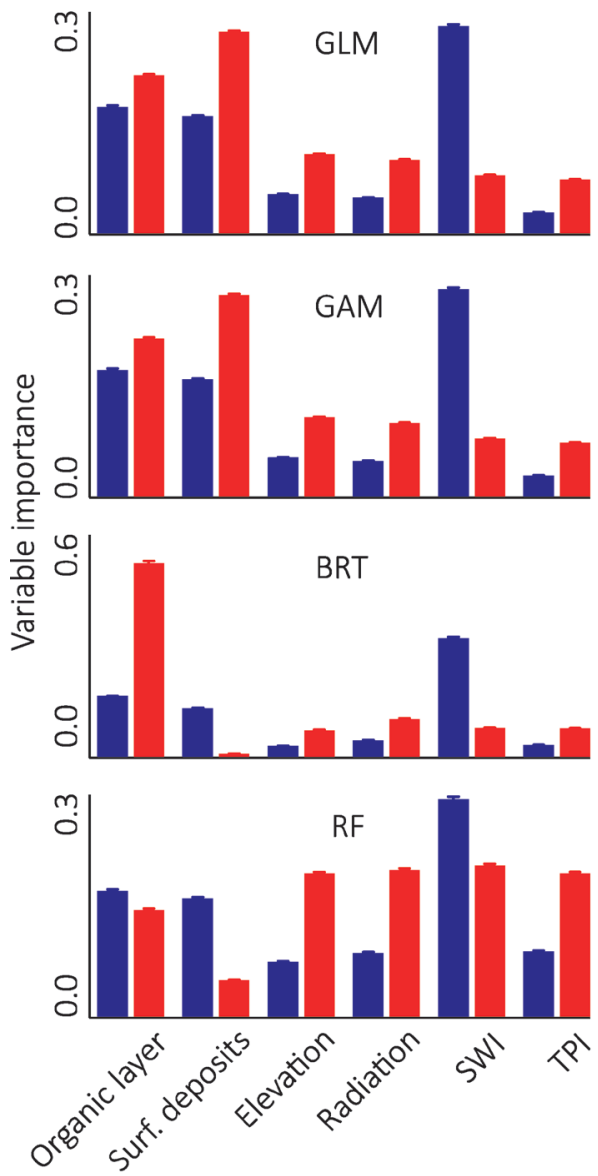

Soil moisture

Temporal variation
B)
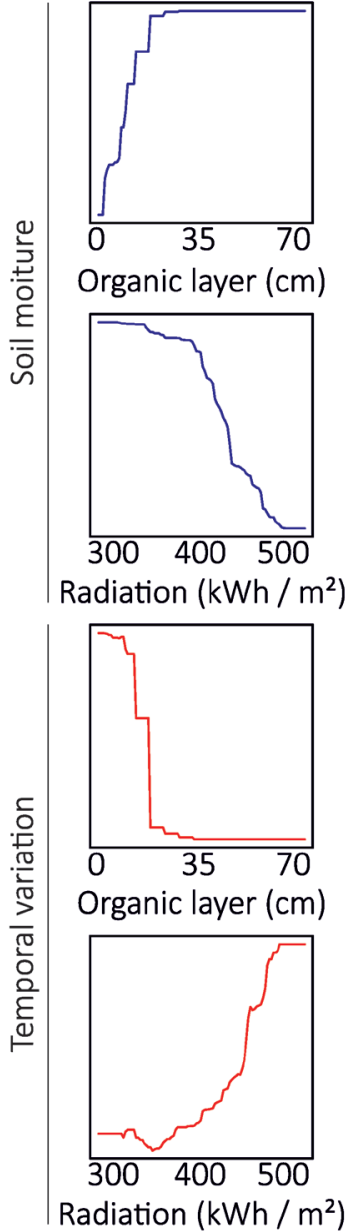

Surficial deposits:

1) Peat 2) Fluvial 3) Glacial till 4) Boulders 5) Rock outcrops

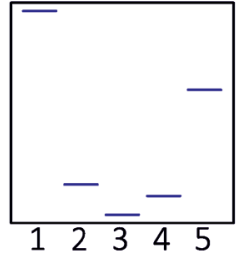

Surficial deposits
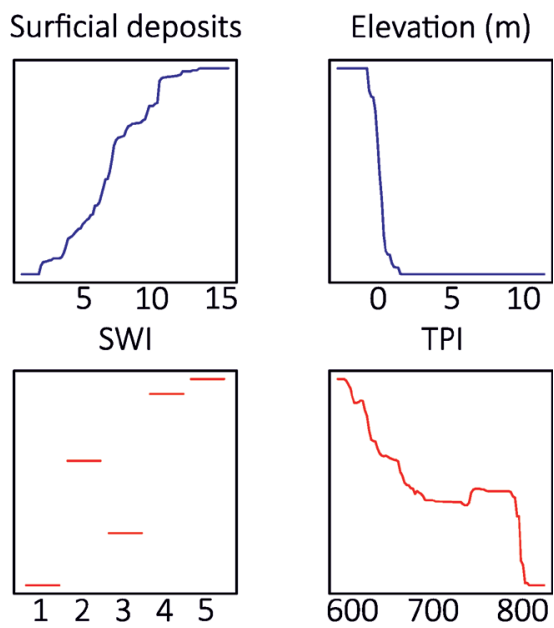

Surficial deposits
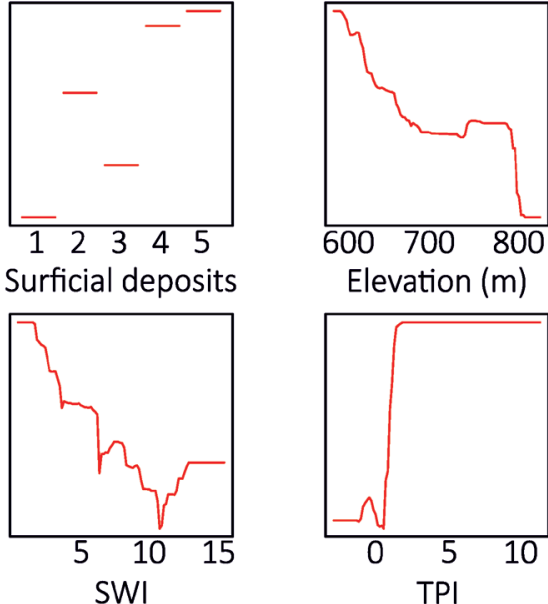

Elevation (m)

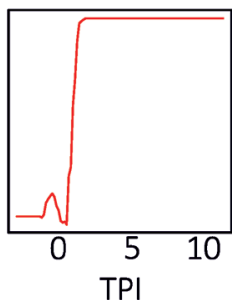

Figure 6. Variable importance $(\mathrm{A})$ and BRT based response curves $(\mathrm{B})$. All modelling methods indicated that SWI was the strongest predictor of soil moisture, with additional important effects from soil properties (A). The results were similar when modelling individual campaigns as well (Supplementary Material Appendix H). For temporal variation, the importance of a predictor variable was not as clear, as their relative influence values depended on the modelling method (A). Error bars show the confidence interval of 95\%. Response curves showed opposite results for soil moisture and its temporal variation (B). For example, thick organic layers indicate high soil moisture, but low temporal variation of soil moisture. This figure is available in colour at wileyonlinelibrary.com/journal/espl.

the highest soil moisture values, whereas low soil moisture prevailed in areas covered by glacial till and boulders (Figure 6B). Elevation had a positive correlation with soil moisture, whereas radiation and TPI had the opposite (Figure 6B). These three topography predictors had a minor influence in the soil moisture models (Figure 6A). Models of individual campaigns showed similar results: soil moisture is mainly depicted by SWI (Supplementary Material Appendix H).

According to GLM, GAM, and BRT, the temporal variation models were strongly influenced by organic layer depth (Figure 6A), with higher temporal variation found in thin layers (Figure 6B). The importance of other predictor variables was not as clear, as their relative influence was dependent on the modelling method (Figure 6A). GLM and GAM stressed the importance of surficial deposits, which showed low temporal variation in peat deposits and higher variation in areas with boulders or rock outcrops. BRT indicated that surficial deposits had the least influence on temporal variation. RF proposed elevation, radiation, SWI, and TPI having a greater influence on temporal variation over organic layer depth. SWI and elevation showed negative correlation with temporal variation, whereas radiation and TPI showed the opposite.

\section{Discussion}

Our results demonstrate great spatial soil moisture variation over short distances across this high-latitude landscape (Figure 3). Fine-scale variation of soil moisture is controlled by both soil and land surface properties, with LiDAR based SWI being the most important predictor in our spatial soil moisture models (Figure 6A). Our results demonstrate a robust pattern based on four statistical modelling methods and three model evaluation methods, indicating that these predictors can be used to produce spatial soil moisture estimates across high-latitude mountain landscapes (Figure 7; Supplementary Material Appendix I). In addition to our initial questions 
presented in the beginning of our work, we found that SWI outperforms the commonly used TWI in modelling soil moisture (Supplementary material Appendix F).

Soil moisture distribution is highly heterogeneous not only in hilly terrains (le Roux et al. 2013), but also in relatively flat plains as well (Engstrom et al. 2005). Our results support previous high-resolution studies, which have documented strong topographic control over soil moisture in montane systems with relatively steep environmental gradients and complex topography (e.g., Isard 1986, Lookingbill and Urban 2004, Milledge et al. 2013). Crave and GascuelOdoux (1997) demonstrated that the use of topography information is insufficient in varying soil conditions. Whereas in our study area with diverse soil depth and soil texture, the most important predictor of spatial soil moisture variation was SWI across methods as well as campaigns (Figure 6A; Supplementary Material Appendix H). SWI showed a high statistically significant positive correlation with the soil moisture measurements (Figure 4).

The general, steady-state soil moisture patterns are captured by topography-based wetness indices, e.g., TWI (Southee et al. 2012, Ågren et al. 2014) and depth-to-water index (Murphy et al. 2009, Oltean et al. 2016). Thus, they are common surrogates in lack of field-obtained soil moisture data (Western et al. 2002, Seneviratne et al. 2010). Yet, in previous studies by Penna et al. (2009) and le Roux et al. (2013) TWI has performed poorly in similar plot sizes and environmental conditions, i.e. rugged terrain and steep slopes. This may be due to several reasons, for instance rain events during soil moisture measurements (Western et al. 2002), varying soil conditions across the study area (Jutras and Arp 2011, Oltean et al. 2016), or the chosen flow accumulation algorithm (Kopecký and Č́ž̌ková 2010). In addition, the soil moisture state itself is also an important factor, as water must first build up in the soil for it to flow from ridges to depressions, i.e. precipitation must exceed evapotranspiration (Grayson and Western 2001). Therefore, two issues should be taken into account when comparing our results to other studies. Firstly, wetness index performance is partly determined by the algorithm used (e.g., Sørensen et al. 2006, Buchanan et al. 2014). We chose to use SWI instead of TWI, as the modified specific catchment area (SCAM) algorithm used in the SWI (Böhner and Selige 2006) seemed to work better compared to the unmodified SCA (Freeman 1991) (Supplementary Material Appendix F). This may be because SWI is designed to take into account flat areas in particular; however, more research is needed to validate the suitable algorithms with field-obtained data. Secondly, we used topography variables based on $1 \mathrm{~m}$ resolution DTM derived from LiDAR data, with the resolution equal to the size of our study plots $\left(1 \mathrm{~m}^{2}\right)$. Based on these results, we recommend considering high-resolution SWI as a proxy of fine-scale soil moisture distribution, when field-obtained data is unavailable.

LiDAR is a superior tool for mapping topography in detail (Southee et al. 2012). The benefits of LiDAR are based on its capacity to detect minor terrain features, for instance hill tops, ridges, small depressions, and meltwater outlets, which are key determinants of fine-scale soil moisture variation (Engstrom et al. 2005, Kammer et al. 2013; but see also Lookingbill \& Urban 2004). Thus, high-resolution LiDAR based soil moisture surrogates are more accurate (Southee et al. 2012, Leempoel et al. 2015) compared to coarser resolution surrogates, which are based on conventional digital elevation models instead of LiDAR data (Murphy et al. 2009). However, the optimal resolution of topography variables is dependent on the size of the terrain features (Lookingbill and Urban 2004, Sørensen and Seibert 2007). Nonetheless, more research is needed in different landscapes, at various resolutions and with different wetness index algorithms (Murphy et al. 2011).

In addition to land surface properties, soil moisture is also influenced by soil properties as well (Figure 6A) (Crave and Gascuel-Odoux 1997). Organic layer depth shows a significant positive correlation with soil moisture (Figure 4). Soil moisture and organic soils have a strong positive feedback: organic soils are formed in wet ground conditions, and they can hold more moisture compared to mineral soils, which have more efficient drainage due to their coarser texture (e.g., Cosby et al. 1984, Darmody et al. 2004, Legates et al. 2011). In the study area, soil moisture increases as the organic layers deepen, up to the saturation point at ca. 30 $\mathrm{cm}$, after which the effect levels off (Figure 6B). In addition to the point-measured organic layer depth, surficial deposits highlight the importance of organic soils: peat deposits had the highest soil moisture content (Figure 6B).

Compared to soil properties and SWI, other terrain data based predictors, namely elevation, radiation, and TPI, were less important for soil moisture variation (Figure 6A). However, the responses of these predictors support previous studies as follows (Figure 6B). High soil moisture content is found in areas of low radiation and are therefore less exposed to surface warming and excess evaporation (Dai et al. 2004). Soil moisture decreases with increasing amount of radiation (Isard 1986), which supports the study by Aalto et al. (2013): soil moisture has a strong negative correlation with soil temperature in high-latitude montane systems. Relative topographic position leads to differences in spatial soil moisture distribution (Engstrom et al. 2005), as it affects a range of environmental variables, such as wind exposition as well as snow and organic matter accumulation. Depressions accumulate water, while ridges tend, by comparison, to be drier (Weiss 2001), which was visible from the response curves (Figure 6B). Elevation had a negative relation with soil moisture, which we assumed to be a combined effect of several environmental gradients, which follow the zonation 
created by elevation, namely climate, vegetation, and soil formation (e.g., Amundson et al. 1989, Lenoir et al. 2008).

While the soil and land surface -based soil moisture predictions performed moderate, these static predictors alone are less suited for predicting temporal variation of soil moisture. Our results suggest that temporal variation is mainly controlled by organic layer depth, with deeper layers indicating less temporal variation in soil moisture (Figure $6 \mathrm{~B})$. The relationship between temporal variation and surficial deposits highlights the influence of organic soils: compared to peat deposits all other classes experienced more variation, exposed rock outcrops in particular (Figure 6B). Due to their higher water holding capacity, organic soils are more resistant to excess evaporation caused by e.g., wind A) Soil moisture (VWC\%)
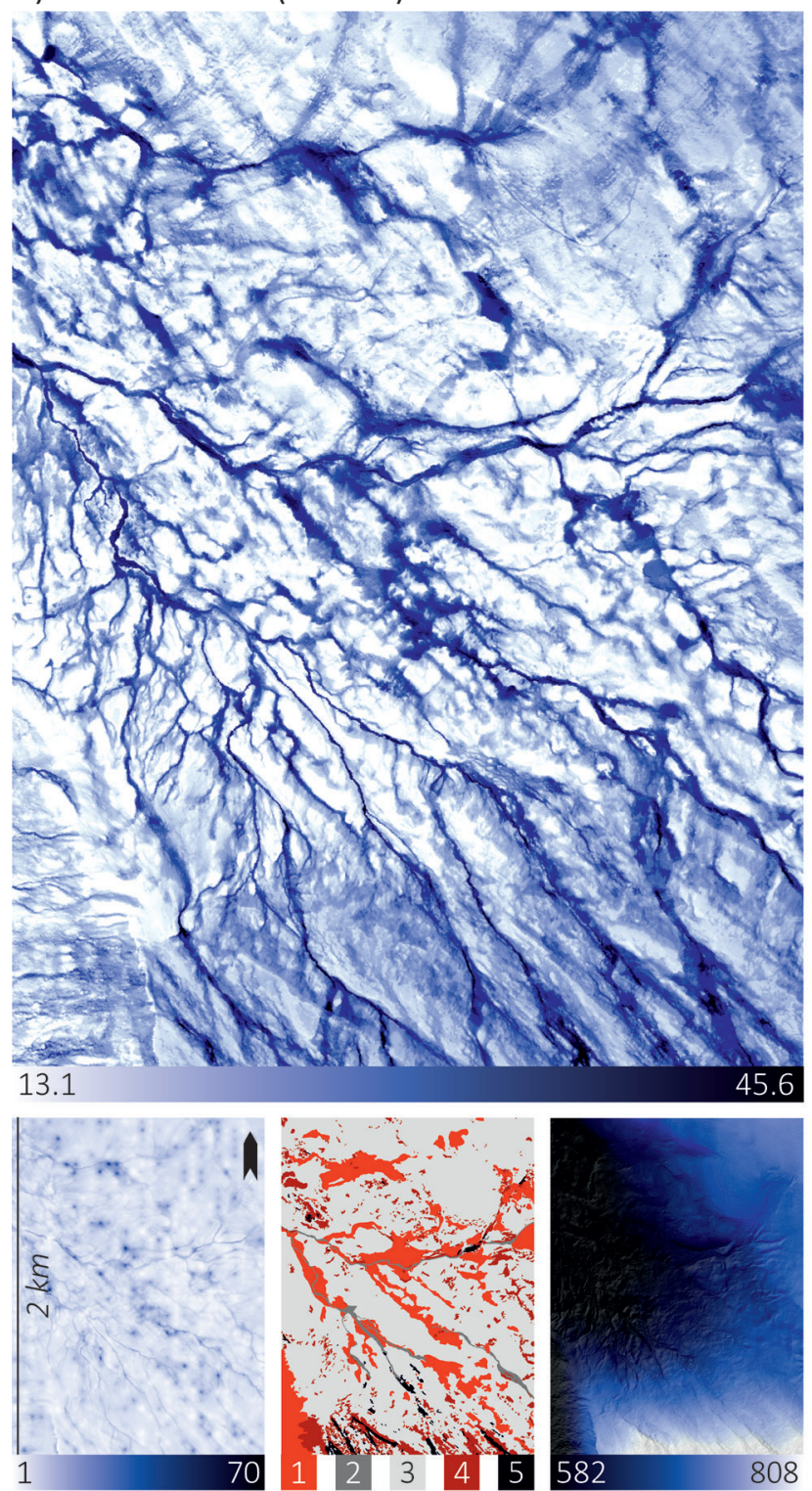

C) Organic layer depth $(\mathrm{cm})$

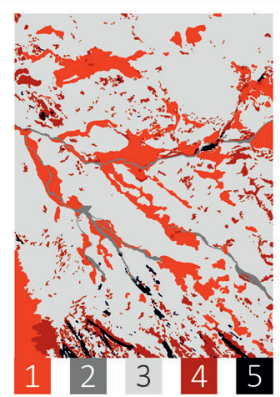

D) Surficial deposits:

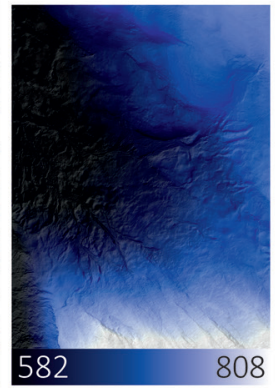

E) Elevation $(m)$ and radiation (Hinkel et al. 2001, Moeslund et al. 2013). In addition, the results demonstrated that areas exposed to strong radiation experienced more temporal variation than shaded areas (Figure 6B).

We examined solely static soil and land surface properties controlling temporal variation of soil moisture, though it has been previously assessed mainly with climatic variables, for instance precipitation events and hydrological seasons (e.g., Wilson et al. 2004, Williams et al. 2009, Garcia-Estringana et al. 2013, Mihailović et al. 2016). In addition to climatic factors, the inclusion of biotic factors may also improve the temporal variation models (Lookingbill and Urban 2004, Emanuel et al. 2014), as vegetation may offset the increases in evaporative water losses in soils (Zavaleta et al. 2003, Aalto B) Temporal variation (CV\%)
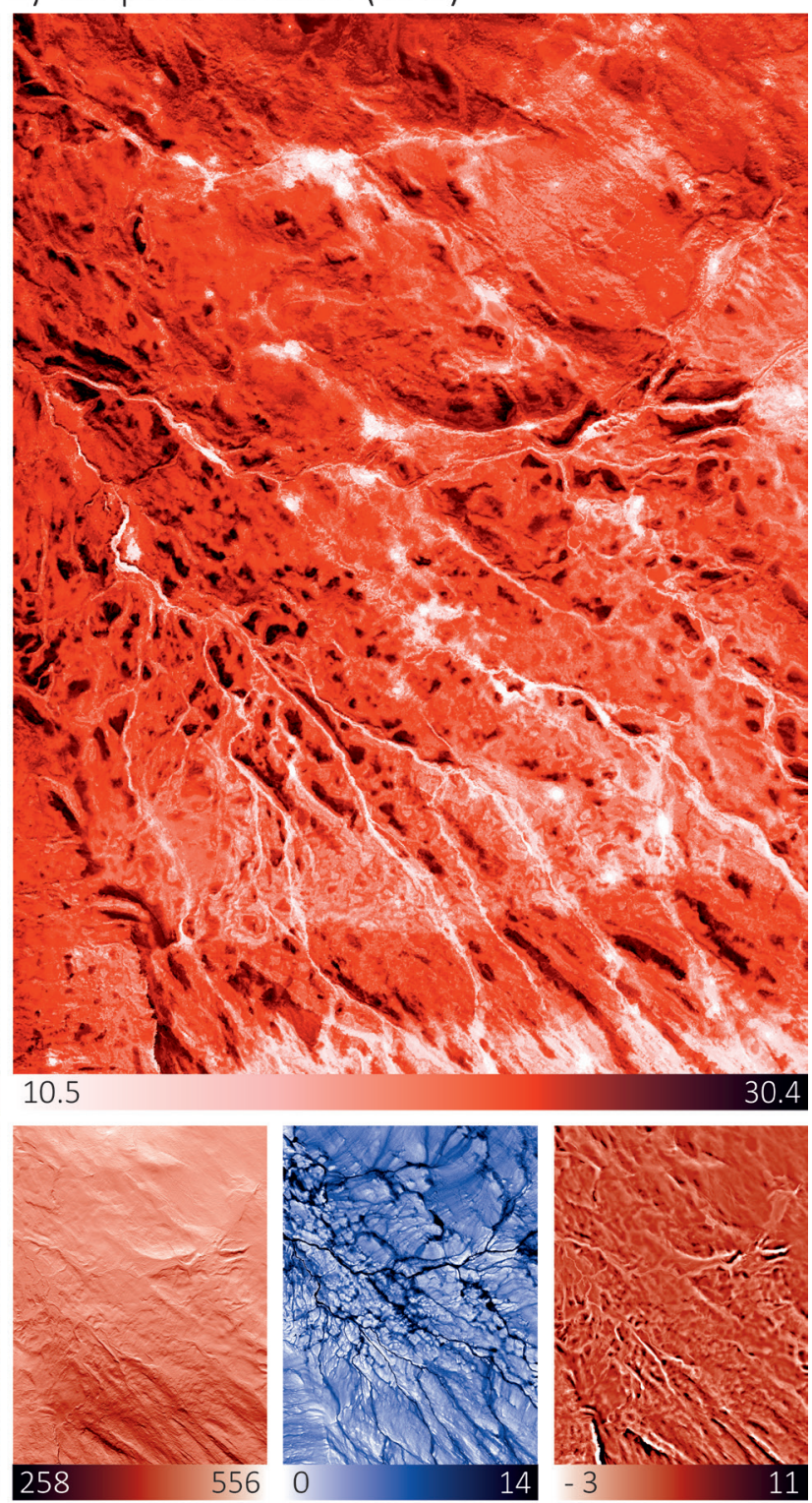

F) Radiation

$\left(\mathrm{kWh} / \mathrm{m}^{2}\right)$

1) Peat 2) Fluvial 3) Glacial till 4) Boulders 5) Rock outcrops

Figure 7. Predicted soil moisture (A) and its temporal variation (B), i.e. the mean of the three measurements and the coefficient of variation, respectively (BRT). The scale of the 1200 organic layer depth measurements (C) and the surficial deposit classification (D; based on 0.5 $\mathrm{m}$ resolution aerial image provided by the National Land Survey of Finland) are comparable with the other predictor variables: land surface variables based on $1 \mathrm{~m}$ resolution LiDAR data $(\mathrm{E}-\mathrm{H})$. This figure is available in colour at wileyonlinelibrary.com/journal/espl 
et al. 2013). Nonetheless, more attention should be drawn to model the temporal variation of soil moisture, as it is an important topic, but not thoroughly investigated yet, especially regarding high-latitude environments. Thus, we encourage considering novel remote sensing methods and data (e.g., Sentinel 1 radar imaging satellites), and soil moisture surrogate algorithms, as these innovations may further promote the use of soil moisture in the spatio-temporal research of the environment (Kopecký and Č́́žková 2010, Leempoel et al. 2015, Griesfeller et al. 2016).

\section{Conclusions}

In this study, we examined soil moisture in a heterogeneous high-latitude tundra landscape covering an extensive soil moisture gradient. We investigated the spatio-temporal heterogeneity of soil moisture using soil and land surface predictors to estimate soil moisture variation. Firstly, we demonstrate fine-scale heterogeneity of spatio-temporal soil moisture patterns in this high-latitude environment. Secondly, our study supports the use of LiDAR based SWI for detecting land surface features in explaining fine-scale soil moisture variation. Thus, we would like to stress the benefits of highresolution predictors, LiDAR based in particular. Thirdly, our results show that soil and land surface properties are important when investigating soil moisture variation in high-latitude landscapes. Therefore, these high-resolution variables can be used as first filter estimates of landscape scale soil moisture conditions.

We stress that more focus is needed to investigate the effect of other fine-scale drivers, optimal resolution, and different topography-based wetness proxies in future soil moisture research. Our work contributes to understand the drivers of high-latitude soil moisture variation, while also promoting the applicability of high-resolution terrain data in modelling soil moisture patterns in different environments.

\section{Acknowledgements}

J. Kemppinen and H. Riihimäki were funded by the Doctoral Program in Geosciences of the University of Helsinki, and P. Niittynen by Kone Foundation and Societas pro Fauna et Flora Fennica. We acknowledge the funding from the Academy of Finland (project 286950). We thank our collaboration partners at the National Land Survey of Finland and the Finnish Meteorological Institute, the former provided us the LiDAR data and the latter the meteorological data. We thank Annina Niskanen for improving the language of the manuscript. And we are grateful for our relentless BioGeoClimate Modelling Lab, our field assistants, and the kind staff at the Kilpisjärvi
Biological Station for all their hard-work, help, and support. We thank our two anonymous reviewers for their time, and their boosting and constructive comments.

\section{References}

Aalto, J., P. C. le Roux, and M. Luoto. 2013. Vegetation Mediates Soil Temperature and Moisture in Arctic-Alpine Environments. Arctic Antarctic and Alpine Research 45:429-439. DOI: 10.1657/1938-4246-45.4.429.

Aalto, J., and M. Luoto. 2014. Integrating climate and local factors for geomorphological distribution models. Earth Surface Processes and Landforms 39:1729-1740. DOI: 10.1002/esp.3554.

Ackerman, D., D. Griffin, S. E. Hobbie, and J. C. Finlay. 2017. Arctic shrub growth trajectories differ across soil moisture levels. Global Change Biology 23:4294 4302. DOI: 10.1111/ gcb.13677.

Ahmad, S., A. Kalra, and H. Stephen. 2010. Estimating soil moisture using remote sensing data: A machine learning approach. Advances in Water Resources 33:69-80. DOI: 10.1016/j. advwatres.2009.10.008.

Ali, I., F. Greifeneder, J. Stamenkovic, M. Neumann, and C. Notarnicola. 2015. Review of Machine Learning Approaches for Biomass and Soil Moisture Retrievals from Remote Sensing Data. Remote Sensing 7:16398-16421. DOI: 10.3390/ rs71215841.

Amundson, R. G., O. A. Chadwick, and J. M. Sowers. 1989. A COMPARISON OF SOIL CLIMATE AND BIOLOGICALACTIVITY ALONG AN ELEVATION GRADIENT IN THE EASTERN MOJAVE DESERT. Oecologia 80:395-400. DOI: 10.1007/bf00379042.

Andresen, C. G., and V. L. Lougheed. 2015. Disappearing Arctic tundra ponds: Fine-scale analysis of surface hydrology in drained thaw lake basins over a 65year period (1948-2013). Journal of Geophysical Research-Biogeosciences 120:466-479. DOI: 10.1002/2014jg002778.

Araújo, M. B., and M. New. 2007. Ensemble forecasting of species distributions. Trends Ecol Evol 22:42-47. DOI: 10.1016/j. tree.2006.09.010.

Ashcroft, M. B., and J. R. Gollan. 2012. Fine-resolution (25 m) topoclimatic grids of near-surface $(5 \mathrm{~cm})$ extreme temperatures and humidities across various habitats in a large $(200 \times 300$ $\mathrm{km})$ and diverse region. International Journal of Climatology 32:2134-2148. DOI: $10.1002 /$ joc. 2428.

Berg, A., K. Findell, B. Lintner, A. Giannini, S. I. Seneviratne, B. van den Hurk, R. Lorenz, A. Pitman, S. Hagemann, A. Meier, F. Cheruy, A. Ducharne, S. Malyshev, and P. C. D. Milly. 2016. Land-atmosphere feedbacks amplify aridity increase over land under global warming. Nature Climate Change 6:869-875. DOI: 10.1038/Nclimate3029.

Beven, K. J., and M. J. Kirkby. 1979. A physically based, variable contributing area model of basin hydrology. Hydrological Sciences Bulletin 24:1:43.

Bintanja, R., and O. Andry. 2017. Towards a rain-dominated Arctic. Nature Climate Change 7:263-+. DOI: 10.1038/nclimate3240.

Blankinship, J. C., M. W. Meadows, R. G. Lucas, and S. C. Hart. 2014. Snowmelt timing alters shallow but not deep soil moisture in the Sierra Nevada. Water Resources Research 50:1448. DOI: 10.1002/2013wr014541.

Breiman, L. 2001. Random forests. Machine Learning 45:5-32. DOI: Doi 10.1023/A:1010933404324.

Brenning, A. 2008. Statistical geocomputing combining R and SAGA: The example of landslide susceptibility analysis with generalized additive models. Pages 23-32 in J. Boehner, T. Blaschke, and L. Montanarella, editors. SAGA - Seconds Out (= Hamburger Beitraege zur Physischen Geographie und Landschaftsoekologie, vol. 19).

Brown, C. E. 1998. Applied Multivariate Statistics in Geohydrology and Related Sciences. Springer Berlin Heidelberg, Berlin, 
Germany.

Buchanan, B. P., M. Fleming, R. L. Schneider, B. K. Richards, J. Archibald, Z. Qiu, and M. T. Walter. 2014. Evaluating topographic wetness indices across central New York agricultural landscapes. Hydrology and Earth System Sciences 18:32793299. DOI: 10.5194/hess-18-3279-2014.

Böhner, J., and O. Antonic. 2009. Land surface parameters specific to topo-climatology. Elsevier, Amsterdam.

Böhner, J., and T. Selige. 2006. Spatial prediction of soil attributes using terrain analysis and climate regionalisation. Page 13 in J. Böhner, K. R. McCloy, and J. Strobl, editors. SAGA Analysis and Modelling Applications. Göttinger Geographische Abhandlungen.

Conrad, O., B. Bechtel, M. Bock, H. Dietrich, E. Fischer, L. Gerlitz, J. Wehberg, V. Wichmann, and J. and Böhner. 2015. System for Automated Geoscientific Analyses (SAGA) v. 2.1.4, Geosci. Model Dev., 8, 1991-2007, doi:10.5194/gmd-8-1991-2015.

Cosby, B. J., G. M. Hornberger, R. B. Clapp, and T. R. Ginn. 1984. A Statistical Exploration of the Relationships of SoilMoisture Characteristics to the Physical-Properties of Soils. Water Resources Research 20:682-690. DOI: 10.1029/ WR020i006p00682.

Crave,A., and C. Gascuel-Odoux. 1997. The influence of topography on time and space distribution of soil surface water content Hydrological Processes 11:203-210. DOI: 10.1002/(Sici)10991085(199702)11:2<203::Aid-Hyp432>3.3.Co;2-B.

Dahlgren, R. A., J. L. Boettinger, G. L. Huntington, and R. G. Amundson. 1997. Soil development along an elevational transect in the western Sierra Nevada, California. Geoderma 78:207-236. DOI: 10.1016/s0016-7061(97)00034-7.

Dai, A., K. E. Trenberth, and T. T. Qian. 2004. A global dataset of Palmer Drought Severity Index for 1870-2002: Relationship with soil moisture and effects of surface warming. Journal of Hydrometeorology 5:1117-1130. DOI: Doi 10.1175/Jhm-386.1.

Dai, A. G. 2011. Drought under global warming: a review. Wiley Interdisciplinary Reviews-Climate Change 2:45-65. DOI: 10.1002/wcc.81.

Dai, A. G. 2013. Increasing drought under global warming in observations and models. Nature Climate Change 3:52-58. DOI: 10.1038/nclimate1633.

Darmody, R. G., C. E. Thorn, P. Schlyter, and J. C. Dixon. 2004. Relationship of vegetation distribution to soil properties in Karkevagge, Swedish Lapland. Arctic Antarctic and Alpine Research 36:21-32. DOI: Doi 10.1657/1523-0430(2004)036[0021:Rovdts]2.0.Co;2.

Elith, J., J. R. Leathwick, and T. Hastie. 2008. A working guide to boosted regression trees. J Anim Ecol 77:802-813. DOI: 10.1111/j.1365-2656.2008.01390.x.

Emanuel, R. E., A. G. Hazen, B. L. McGlynn, and K. G. Jencso. 2014. Vegetation and topographic influences on the connectivity of shallow groundwater between hillslopes and streams. Ecohydrology 7:887-895. DOI: 10.1002/eco.1409.

Engstrom, R., A. Hope, H. Kwon, D. Stow, and D. Zamolodchikov. 2005. Spatial distribution of near surface soil moisture and its relationship to microtopography in the Alaskan Arctic coastal plain. Nordic Hydrology 36:219-234.

Esri. 2012. ArcGIS 10 Desktop Help. <http //hel arcgis.com/En/ Arcgisdesktop/10.0/Help/>.

Falloon, P., C. D. Jones, M. Ades, and K. Paul. 2011. Direct soil moisture controls of future global soil carbon changes: An important source of uncertainty. Global Biogeochemical Cycles 25:GB3010. DOI: 10.1029/2010gb003938.

Famiglietti, J. S., J. W. Rudnicki, and M. Rodell. 1998. Variability in surface moisture content along a hillslope transect: Rattlesnake Hill, Texas. Journal of Hydrology 210:259-281. DOI: Doi 10.1016/S0022-1694(98)00187-5.

Famiglietti, J. S., D. Ryu, A. A. Berg, M. Rodell, and T. J. Jackson. 2008. Field observations of soil moisture variability across scales. Water Resources Research 44:W01423. DOI: 10.1029/2006wr005804.

Fisher, J. P., C. Estop-Aragones, A. Thierry, D. J. Charman, S. A. Wolfe, I. P. Hartley, J. B. Murton, M. Williams, and G. K. Phoenix.
2016. The influence of vegetation and soil characteristics on active-layer thickness of permafrost soils in boreal forest. Glob Chang Biol 22:3127-3140. DOI: 10.1111/gcb.13248.

Fox, J. 2015. polycor: Polychoric and Polyserial Correlations. $\mathrm{R}$ package version $0.7-8$. < http //CRAN.R-project.org/ package $=$ polycor $>$.

Franklin, J. 2010. Mapping species distributions. Cambridge University Press, Cambridge, Yhdistynyt kuningaskunta.

Freeman, T. G. 1991. CALCULATING CATCHMENT-AREA WITHDIVERGENTFLOWBASED ONAREGULAR GRID. Computers \& Geosciences 17:413-422. DOI: 10.1016/00983004(91)90048-i.

Garcia-Estringana, P., J. Latron, P. Llorens, and F. Gallart. 2013. Spatial and temporal dynamics of soil moisture in a Mediterranean mountain area (Vallcebre, NE Spain). Ecohydrology 6:741-753. DOI: $10.1002 /$ eco.1295.

Grayson, R., and A. Western. 2001. Terrain and the distribution of soil moisture. Hydrological Processes 15:2689-2690. DOI: DOI 10.1002/hyp.479.

Grayson, R. B., A. W. Western, F. H. S. Chiew, and G. Bloschl. 1997. Preferred states in spatial soil moisture patterns: Local and nonlocal controls. Water Resources Research 33:2897-2908. DOI: $10.1029 / 97 \mathrm{wr} 02174$

Griesfeller, A., W. A. Lahoz, R. A. M. de Jeu, W. Dorigo, L. E. Haugen, T. M. Svendby, and W. Wagner. 2016. Evaluation of satellite soil moisture products over Norway using groundbased observations. International Journal of Applied Earth Observation and Geoinformation 45:155-164. DOI: 10.1016/j. jag.2015.04.016.

Guisan, A., S. B. Weiss, and A. D. Weiss. 1999. GLM versus CCA spatial modeling of plant species distribution. Plant Ecology 143:107-122. DOI: Doi 10.1023/A:1009841519580.

Hajek, M., P. Hajkova, M. Koci, M. Jirousek, E. Mikulaskova, and K. Kintrova. 2013. Do we need soil moisture measurements in the vegetation-environment studies in wetlands? Journal of Vegetation Science 24:127-137. DOI: 10.1111/j.16541103.2012.01440.x.

Harpold, A. A., and N. P. Molotch. 2015. Sensitivity of soil water availability to changing snowmelt timing in the western US. Geophysical Research Letters 42:8011-8020. DOI: $10.1002 / 2015 \mathrm{gl} 1065855$.

Hastie, T., and R. Tibshirani. 1987. Generalized Additive-Models - Some Applications. Journal of the American Statistical Association 82:371-386. DOI: Doi 10.2307/2289439.

Hauser, M., R. Orth, and S. I. Seneviratne. 2016. Role of soil moisture versus recent climate change for the 2010 heat wave in western Russia. Geophysical Research Letters 43:2819-2826. DOI: $10.1002 / 2016 \mathrm{gl068036.}$

Hedley, C. B., P. Roudier, I. J. Yule, J. Ekanayake, and S. Bradbury. 2013. Soil water status and water table depth modelling using electromagnetic surveys for precision irrigation scheduling. Geoderma 199:22-29. DOI: 10.1016/j.geoderma.2012.07.018.

Hengl, T., G. B. M. Heuvelink, B. Kempen, J. G. B. Leenaars, M. G. Walsh, K. D. Shepherd, A. Sila, R. A. MacMillan, J. M. de Jesus, L. Tamene, and J. E. Tondoh. 2015. Mapping Soil Properties of Africa at $250 \mathrm{~m}$ Resolution: Random Forests Significantly Improve Current Predictions. Plos One 10:26. DOI: 10.1371/ journal.pone.0125814.

Hijmans, R. J. 2015. raster: Geographic Data Analysis and Modeling. $\mathrm{R}$ package version $2.5-2$.

Hinkel, K. M., F. Paetzold, F. E. Nelson, and J. G. Bockheim. 2001. Patterns of soil temperature and moisture in the active layer and upper permafrost at Barrow, Alaska: 1993-1999. Global and Planetary Change 29:293-309. DOI: Doi 10.1016/S09218181(01)00096-0.

Hoover, D. L., and B. M. Rogers. 2016. Not all droughts are created equal: the impacts of interannual drought pattern and magnitude on grassland carbon cycling. Glob Chang Biol 22:1809-1820. DOI: $10.1111 /$ gcb.13161.

Hudson, B. D. 1994. SOILORGANIC-MATTERANDAVAILABLE WATER CAPACITY. Journal of Soil and Water Conservation 49:189-194. 
Huntington, T. G. 2006. Evidence for intensification of the global water cycle: Review and synthesis. Journal of Hydrology 319:8395. DOI: 10.1016/j.jhydrol.2005.07.003.

Isard, S. A. 1986. Factors Influencing Soil-Moisture and Plant Community Distribution on Niwot Ridge, Front Range, Colorado, USA. Arctic and Alpine Research 18:83-96. DOI: Doi 10.2307/1551216.

Isenburg, M. 2017. LAStools - efficient LiDAR processing software (version 170302 , Academic).

Jaboyedoff, M., T. Oppikofer, A. Abellan, M. H. Derron, A. Loye, R. Metzger, and A. Pedrazzini. 2012. Use of LIDAR in landslide investigations: a review. Natural Hazards 61:5-28. DOI: $10.1007 /$ s11069-010-9634-2.

Jaesche, P., H. Veit, and B. Huwe. 2003. Snow cover and soil moisture controls on solifluction in an area of seasonal frost, eastern Alps. Permafrost and Periglacial Processes 14:399-410. DOI: 10.1002/ ppp.471.

Johnson, K. A., and N. Sitar. 1990. Hydrologic Conditions Leading to Debris-Flow Initiation. Canadian Geotechnical Journal 27:789801. DOI: $10.1139 / \mathrm{t} 90-092$.

Jung, M., M. Reichstein, P. Ciais, S. I. Seneviratne, J. Sheffield, M. L. Goulden, G. Bonan, A. Cescatti, J. Chen, R. de Jeu, A. J. Dolman, W. Eugster, D. Gerten, D. Gianelle, N. Gobron, J. Heinke, J. Kimball, B. E. Law, L. Montagnani, Q. Mu, B. Mueller, K. Oleson, D. Papale, A. D. Richardson, O. Roupsard, S. Running, E. Tomelleri, N. Viovy, U. Weber, C. Williams, E. Wood, S. Zaehle, and K. Zhang. 2010. Recent decline in the global land evapotranspiration trend due to limited moisture supply. Nature 467:951-954. DOI: 10.1038/nature09396.

Jutras, M. F., and P. A. Arp. 2011. Determining Hydraulic Conductivity from Soil Characteristics with Applications for Modelling Stream Discharge in Forest Catchments. Pages 189-202 in L. Elango, editor. Hydraulic Conductivity - Issues, Determination and Applications. Intech Europe, Rijeka.

Kammer, P. M., C. Schob, G. Eberhard, R. Gallina, R. Meyer, and C. Tschanz. 2013. The relationship between soil water storage capacity and plant species diversity in high alpine vegetation. Plant Ecology \& Diversity 6:457-466. DOI: 10.1080/17550874.2013.783142.

Kopecký, M., and Š. Č́žžková. 2010. Using topographic wetness index in vegetation ecology: does the algorithm matter? Applied Vegetation Science 13:450-459. DOI: 10.1111/j.1654109X.2010.01083.x.

Korres, W., T. G. Reichenau, P. Fiener, C. N. Koyama, H. R. Bogena, T. Comelissen, R. Baatz, M. Herbst, B. Diekkruger, H. Vereecken, and K. Schneider. 2015. Spatio-temporal soil moisture patterns - A meta-analysis using plot to catchment scale data. Journal of Hydrology 520:326-341. DOI: 10.1016/j. jhydrol.2014.11.042.

Koster, R. D., P. A. Dirmeyer, Z. Guo, G. Bonan, E. Chan, P. Cox, C. T. Gordon, S. Kanae, E. Kowalczyk, D. Lawrence, P. Liu, C. H. Lu, S. Malyshev, B. McAvaney, K. Mitchell, D. Mocko, T. Oki, K. Oleson, A. Pitman, Y. C. Sud, C. M. Taylor, D. Verseghy, R. Vasic, Y. Xue, T. Yamada, and G. Team. 2004. Regions of strong coupling between soil moisture and precipitation. Science 305:1138-1140. DOI: 10.1126/science.1100217.

Kwon, M. J., M. Heimann, O. Kolle, K. A. Luus, E. A. G. Schuur, N. Zimov, S. A. Zimov, and M. Gockede. 2016. Long-term drainage reduces $\mathrm{CO} 2$ uptake and increases $\mathrm{CO} 2$ emission on a Siberian floodplain due to shifts in vegetation community and soil thermal characteristics. Biogeosciences 13:4219-4235. DOI: 10.5194/bg-13-4219-2016.

Lane, P. W. 2002. Generalized linear models in soil science. European Journal of Soil Science 53:241-251. DOI: DOI 10.1046/j.13652389.2002.00440.x.

le Roux, P. C., J. Aalto, and M. Luoto. 2013. Soil moisture's underestimated role in climate change impact modelling in low-energy systems. Glob Chang Biol 19:2965-2975. DOI: 10.1111/gcb.12286.

Leempoel, K., C. Parisod, C. Geiser, L. Dapra, P. Vittoz, and S. Joost. 2015. Very high-resolution digital elevationmodels: are multi-scale derived variables ecologically relevant? Methods in Ecology and Evolution 6:1373-1383. DOI: 10.1111/2041210x.12427.

Legates, D. R., R. Mahmood, D. F. Levia, T. L. DeLiberty, S. M. Quiring,C.Houser, andF.E.Nelson.2011.Soil moisture:Acentral and unifying theme in physical geography. Progress in Physical Geography 35:65-86. DOI: 10.1177/0309133310386514.

Lehtovaara, J. J. 1995. Pre-Quaternary rocks of the Kilpisjärvi and Halti map-sheet areas. Geological Survey of Finland, Espoo.

Lenoir, J., J. C. Gegout, P. A. Marquet, P. de Ruffray, and H. Brisse. 2008. A significant upward shift in plant species optimum elevation during the 20th century. Science 320:1768-1771. DOI: 10.1126/science. 1156831 .

Liaw, A., and M. Wiener. 2002. Classification and Regression by randomForest. R News 2:18-22.

Lookingbill, T., and D. Urban. 2004. An empirical approach towards improved spatial estimates of soil moisture for vegetation analysis. Landscape Ecology 19:417-433. DOI: 10.1023/B:L AND.0000030451.29571.8b.

Marmion, M., M. Parviainen, M. Luoto, R. K. Heikkinen, and W. Thuiller. 2009. Evaluation of consensus methods in predictive species distribution modelling. Diversity and Distributions 15:59-69. DOI: 10.1111/j.1472-4642.2008.00491.x.

Maxwell, R. M., and L. E. Condon. 2016. Connections between groundwater flow and transpiration partitioning. Science 353:377-380. DOI: 10.1126/science.aaf7891.

McBratney, A. B., I. O. A. Odeh, T. F. A. Bishop, M. S. Dunbar, and T. M. Shatar. 2000. An overview of pedometric techniques for use in soil survey. Geoderma 97:293-327. DOI: Doi 10.1016/ S0016-7061(00)00043-4.

McBratney, A. B., M. L. M. Santos, and B. Minasny. 2003. On digital soil mapping. Geoderma 117:3-52. DOI: 10.1016/S00167061(03)00223-4.

McColl, K. A., S. H. Alemohammad, R. Akbar, A. G. Konings, S. Yueh, and D. Entekhabi. 2017. The global distribution and dynamics of surface soil moisture. Nature Geoscience 10:100104. DOI: $10.1038 /$ ngeo 2868 .

Mihailović, D. T., N. Dreškovic, I. Arsenić, V. Ćirić, V. Djurdjević, G. Mimić, I. Pap, and I. Balaž. 2016. Impact of climate change on soil thermal and moisture regimes in Serbia: An analysis with data from regional climate simulations under SRES-A1B. Sci Total Environ 571:398-409. DOI: 10.1016/j.scitotenv.2016.06.142.

Milledge, D. G., J. Warburton, S. N. Lane, and C. J. Stevens. 2013. Testing the influence of topography and material properties on catchment-scale soil moisture patterns using remotely sensed vegetation patterns in a humid temperate catchment, northern Britain. Hydrological Processes 27:1223-1237. DOI: 10.1002/ hyp. 9292.

Mitášova, H., and L. Mitáš. 1993. INTERPOLATION BY REGULARIZED SPLINE WITH TENSION .1. THEORY AND IMPLEMENTATION. Mathematical Geology 25:641655. DOI: $10.1007 / \mathrm{bf} 00893171$.

Moeslund, J. E., L. Arge, P. K. Bocher, T. Dalgaard, R. Ejrnaes, M. V. Odgaard, and J. C. Svenning. 2013. Topographically controlled soil moisture drives plant diversity patterns within grasslands. Biodiversity and Conservation 22:2151-2166. DOI: 10.1007/ s10531-013-0442-3.

Moore, I. D., P. E. Gessler, G. A. Nielsen, and G. A. Peterson. 1993. SOIL ATTRIBUTE PREDICTION USING TERRAIN ANALYSIS. Soil Science Society of America Journal 57:443452. DOI: 10.2136/sssaj1993.03615995005700020026x.

Murphy, P. N. C., J. Ogilvie, and P. Arp. 2009. Topographic modelling of soil moisture conditions: a comparison and verification of two models. European Journal of Soil Science 60:94-109. DOI: 10.1111/j.1365-2389.2008.01094.x.

Murphy, P. N. C., J. Ogilvie, F. R. Meng, B. White, J. S. Bhatti, and P. A. Arp. 2011. Modelling and mapping topographic variations in forest soils at high resolution: Acase study. Ecological Modelling 222:2314-2332. DOI: 10.1016/j.ecolmodel.2011.01.003.

Myers-Smith, I. H., S. C. Elmendorf, P. S. A. Beck, M. Wilmking, M. Hallinger, D. Blok, K. D. Tape, S. A. Rayback, M. MaciasFauria, B. C. Forbes, J. D. M. Speed, N. Boulanger-Lapointe, C. Rixen, E. Lévesque, N. M. Schmidt, C. Baittinger, A. J. 
Trant, L. Hermanutz, L. S. Collier, M. A. Dawes, T. C. Lantz, S. Weijers, R. H. Jørgensen, A. Buchwal, A. Buras, A. T. Naito, V. Ravolainen, G. Schaepman-Strub, J. A. Wheeler, S. Wipf, K. C. Guay, D. S. Hik, and M. Vellend. 2015. Climate sensitivity of shrub growth across the tundra biome. Nature Climate Change 5:887-891. DOI: 10.1038/nclimate2697.

Naghibi, S. A., H. R. Pourghasemi, and B. Dixon. 2016. GIS-based groundwater potential mapping using boosted regression tree, classification and regression tree, and random forest machine learning models in Iran. Environmental Monitoring and Assessment 188:27. DOI: 10.1007/s10661-015-5049-6.

Natali, S. M., E. A. G. Schuur, M. Mauritz, J. D. Schade, G. Celis, K. G. Crummer, C. Johnston, J. Krapek, E. Pegoraro, V. G. Salmon, and E. E. Webb. 2015. Permafrost thaw and soil moisture driving $\mathrm{CO} 2$ and $\mathrm{CH} 4$ release from upland tundra. Journal of Geophysical Research-Biogeosciences 120:525-537. DOI: $10.1002 / 2014 \mathrm{jg} 002872$.

Nelder, J. A., and R. W. Wedderburn. 1972. Generalized Linear Models. Journal of the Royal Statistical Society Series a-General 135:370-+. DOI: Doi 10.2307/2344614.

Odeh, I. O. A., A. B. McBratney, and B. K. Slater. 1997. Predicting soil properties from ancillary information: Non-spatial models compared geostatistical and combined methods. Geostatistics Wollongong '96, Vols 1 and 2 8:1008-1019.

Oltean, G. S., P. G. Comeau, and B. White. 2016. Linking the Depthto-Water Topographic Index to Soil Moisture on Boreal Forest Sites in Alberta. Forest Science 62:154-165. DOI: 10.5849/ forsci.15-054.

Penna, D., M. Borga, D. Norbiato, and G. D. Fontana. 2009. Hillslope scale soil moisture variability in a steep alpine terrain. Journal of Hydrology 364:311-327. DOI: 10.1016/j.jhydrol.2008.11.009.

Pfahl, S., P. A. O'Gorman, and E. M. Fischer. 2017. Understanding the regional pattern of projected future changes in extreme precipitation. Nature Climate Change 7:423-+. DOI: 10.1038/ nclimate3287.

Pirinen, P., H. Simola, J. Aalto, J.-P. Kaukoranta, P. Karlsson, and R. Ruuhela. 2012. Climatological statistics of Finland 1981-2010. Finnish Meteorological Institute, Helsinki.

R Development Core Team. 2016. The R Project for Statistical Computing, Vienna, Austria. <https //www.r-project.org/>.

Ridgeway, G. 2017. gbm: Generalized Boosted Regression Models. $\mathrm{R}$ package version 2.1.3.

Rose, J.P., and G. P. Malanson. 2012. Microtopographic heterogeneity constrains alpine plant diversity, Glacier National Park, MT. Plant Ecology 213:955-965. DOI: 10.1007/s11258-012-0056-y.

Scull, P., J. Franklin, O. A. Chadwick, and D. McArthur. 2003. Predictive soil mapping: a review. Progress in Physical Geography 27:171-197. DOI: 10.1191/0309133303pp366ra.

Seneviratne, S. I., T. Corti, E. L. Davin, M. Hirschi, E. B. Jaeger, I. Lehner, B. Orlowsky, and A. J. Teuling. 2010. Investigating soil moisture-climate interactions in a changing climate: A review. Earth-Science Reviews 99:125-161. DOI: 10.1016/j. earscirev.2010.02.004.

Seneviratne, S. I., D. Luthi, M. Litschi, and C. Schar. 2006. Landatmosphere coupling and climate change in Europe. Nature 443:205-209. DOI: 10.1038/nature05095.

Serreze, M. C., and R. G. Barry. 2011. Processes and impacts of Arctic amplification: A research synthesis. Global and Planetary Change 77:85-96. DOI: 10.1016/j.gloplacha.2011.03.004.

Sitch, S., B. Smith, I. C. Prentice, A. Arneth, A. Bondeau, W. Cramer, J. O. Kaplan, S. Levis, W. Lucht, M. T. Sykes, K. Thonicke, and S. Venevsky. 2003. Evaluation of ecosystem dynamics, plant geography and terrestrial carbon cycling in the LPJ dynamic global vegetation model. Global Change Biology 9:161-185. DOI: DOI 10.1046/j.1365-2486.2003.00569.x.

Smith, L. C., Y. Sheng, G. M. MacDonald, and L. D. Hinzman. 2005. Disappearing Arctic lakes. Science 308:1429-1429. DOI: 10.1126/science. 1108142 .

Smol, J. P., and M. S. Douglas. 2007. Crossing the final ecological threshold in high Arctic ponds. Proceedings of the National Academy of Sciences of the United States of America 104:1239512397. DOI: $10.1073 /$ pnas.0702777104.
Southee, F. M., P. M. Treitz, and N. A. Scott. 2012. Application of Lidar Terrain Surfaces for Soil Moisture Modeling. Photogrammetric Engineering and Remote Sensing 78:12411251. DOI: 10.14358/PERS.78.11.1241.

Spectrum Technologies, I. 2012. TECHNICAL BULLETIN NO. 20120110 www.specmeters.com/assets/1/22/Technical Bulletin_20120110.pdf. 20 September 2017.

Srivastava, P. K., D. W. Han, M. R. Ramirez, and T. Islam. 2013. Machine Learning Techniques for Downscaling SMOS Satellite Soil Moisture Using MODIS Land Surface Temperature for Hydrological Application. Water Resources Management 27:3127-3144. DOI: 10.1007/s11269-013-0337-9.

Sylvain, Z. A., D. H. Wall, K. L. Cherwin, D. P. C. Peters, L. G. Reichmann, and O. E. Sala. 2014. Soil animal responses to moisture availability are largely scale, not ecosystem dependent: insight from a cross-site study. Global Change Biology 20:26312643. DOI: $10.1111 / \mathrm{gcb} .12522$.

Sørensen, R., and J. Seibert. 2007. Effects of DEM resolution on the calculation of topographical indices: TWI and its components. Journal of Hydrology 347:79-89. DOI: 10.1016/j. jhydrot.2007.09.001.

Sørensen, R., U. Zinko, and J. Seibert. 2006. On the calculation of the topographic wetness index: evaluation of different methods based on field observations. Hydrology and Earth System Sciences 10:101-112. DOI: 10.5194/hess-10-101-2006.

Teuling, A. J., and P. A. Troch. 2005. Improved understanding of soil moisture variability dynamics. Geophysical Research Letters 32:L05404. DOI: Artn L05404

10.1029/2004gl021935.

Thuiller, W., B. Lafourcade, R. Engler, and M. B. Araujo. 2009. BIOMOD - a platform for ensemble forecasting of species distributions. Ecography 32:369-373. DOI: $10.1111 /$ j.16000587.2008.05742.x.

Trahan, M. W., and B. A. Schubert. 2016. Temperature-induced water stress in high-latitude forests in response to natural and anthropogenic warming. Glob Chang Biol 22:782-791. DOI: 10.1111/gcb.13121.

Tromp-van Meerveld, H. J., and J. J. McDonnell. 2006. On the interrelations between topography, soil depth, soil moisture, transpiration rates and species distribution at the hillslope scale. Advances in Water Resources 29:293-310. DOI: 10.1016/j. advwatres.2005.02.016.

Trumbore, S. E., O. A. Chadwick, and R. Amundson. 1996. Rapid exchange between soil carbon and atmospheric carbon dioxide driven by temperature change. Science 272:393-396. DOI: 10.1126/science.272.5260.393.

Tuttle, S., and G. Salvucci. 2016. Empirical evidence of contrasting soil moisture-precipitation feedbacks across the United States. Science 352:825-828. DOI: 10.1126/science.aaa7185.

Wang, L., and H. Liu. 2006. An efficient method for identifying and filling surface depressions in digital elevation models for hydrologic analysis and modelling. International Journal of Geographical Information Science 20:193-213. DOI: $10.1080 / 13658810500433453$.

Wehr, A., and U. Lohr. 1999. Airborne laser scanning - an introduction and overview. Isprs Journal of Photogrammetry and Remote Sensing 54:68-82. DOI: Doi 10.1016/S0924-2716(99)00011-8.

Weiss, A. D. 2001. Topographic position and landforms analysis. ESRI Users Conference, San Diego, California, USA.

Western, A. W., R. B. Grayson, and G. Bloschl. 2002. Scaling of soil moisture: A hydrologic perspective. Annual Review of Earth and Planetary Sciences 30:149-180. DOI: DOI 10.1146/annurev. earth.30.091201.140434.

Williams, C. J., J. P. McNamara, and D. G. Chandler. 2009. Controls on the temporal and spatial variability of soil moisture in a mountainous landscape: the signature of snow and complex terrain. Hydrology and Earth System Sciences 13:1325-1336. DOI: $10.5194 /$ hess-13-1325-2009.

Wilson, D. J., A. W. Western, and R. B. Grayson. 2004. Identifying and quantifying sources of variability in temporal and spatial soil moisture observations. Water Resources Research 40:W02507. DOI: $10.1029 / 2003$ wr002306. 
Wilson, J. P., and J. C. Gallant. 2000. Terrain analysis: Principles and Applications. John Wiley \& Sons, Inc., New York, USA.

Winkler, D. E., K. J. Chapin, and L. M. Kueppers. 2016. Soil moisture mediates alpine life form and community productivity responses to warming. Ecology 97:1553-1563. DOI: 10.1890/15-1197.1.

Wood, S. N. 2011. Fast stable restricted maximum likelihood and marginal likelihood estimation of semiparametric generalized linear models. Journal of the Royal Statistical Society Series B-Statistical Methodology 73:3-36. DOI: 10.1111/j.14679868.2010.00749.x.

Xu, W. F., W. P. Yuan, W. J. Dong, J.Z. Xia, D. Liu, and Y. Chen. 2013 A meta-analysis of the response of soil moisture to experimental warming. Environmental Research Letters 8:044027. DOI: 10.1088/1748-9326/8/4/044027.

Zambrano-Bigiarini, M. 2017. hydroGOF: Goodness-of-fit functions for comparison of simulated and observed hydrological time seriesR package version $0.3-10$

Zavaleta, E. S., B. D. Thomas, N. R. Chiariello, G. P. Asner, M. R. Shaw, and C. B. Field. 2003. Plants reverse warming effect on ecosystem water balance. Proceedings of the National Academy of Sciences of the United States of America 100:9892-9893. DOI: $10.1073 /$ pnas. 1732012100 .

Zevenbergen, L. W., and C. R. Thorne. 1987. Quantitative-Analysis of Land Surface-Topography. Earth Surface Processes and Landforms 12:47-56. DOI: DOI 10.1002/esp.3290120107.

Ågren, A. M., W. Lidberg, M. Stromgren, J. Ogilvie, and P. A. Arp. 2014. Evaluating digital terrain indices for soil wetness mapping - a Swedish case study. Hydrology and Earth System Sciences 18:3623-3634. DOI: 10.5194/hess-18-3623-2014.

\section{Supplementary Material Appendix A}

\author{
Calibration moisture ("CM") \\ = A transect of 25 points one meter apart from each other \\ on a moisture gradient located on a mesotopographically \\ complex terrain measured daily before and after soil \\ moisture campaigns.
}

\author{
Soil moisture ("SM") \\ = A grid of 1200 plots measured on moisture campaigns \\ lasting three to five consecutive days.
}

Calculate the relative change for each transect point throughout the campaign, using the first measurement as the point of reference.

\section{Calculate the average of changes occured on all 25 points ("CHANGE").}

Create a time series starting from midnight (00:00) before the first moisture campaign day. Locate each measurement on the time series ("TIME").

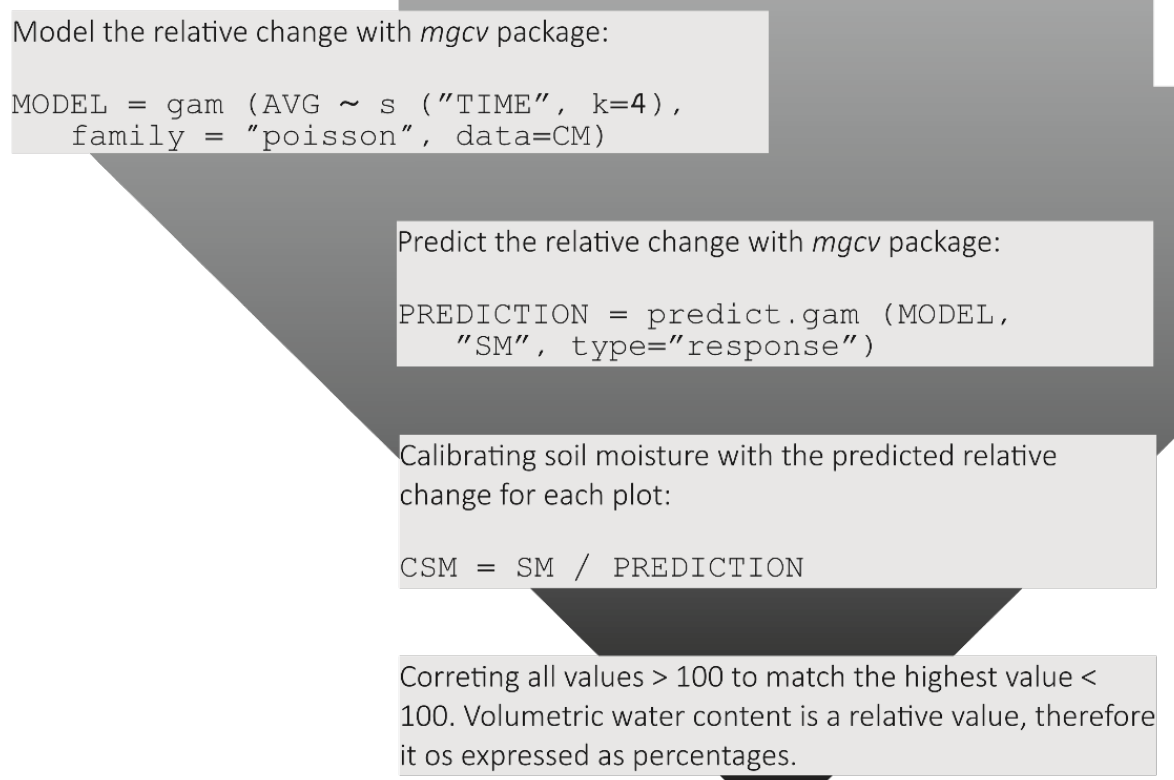

Workflow for calibration. After calibrating the data, we found that the difference between observed and calibrated values was rather subtle, only 0.5 VWC $\%$ on the average (Supplementary Material Appendix B). Thus, we decided to use uncalibrated moisture values for all analyses, for consistency and comparability between campaigns. All calculations were executed in R. This figure is available in colour at wileyonlinelibrary.com/journal/espl 


\section{Supplementary Material Appendix B}
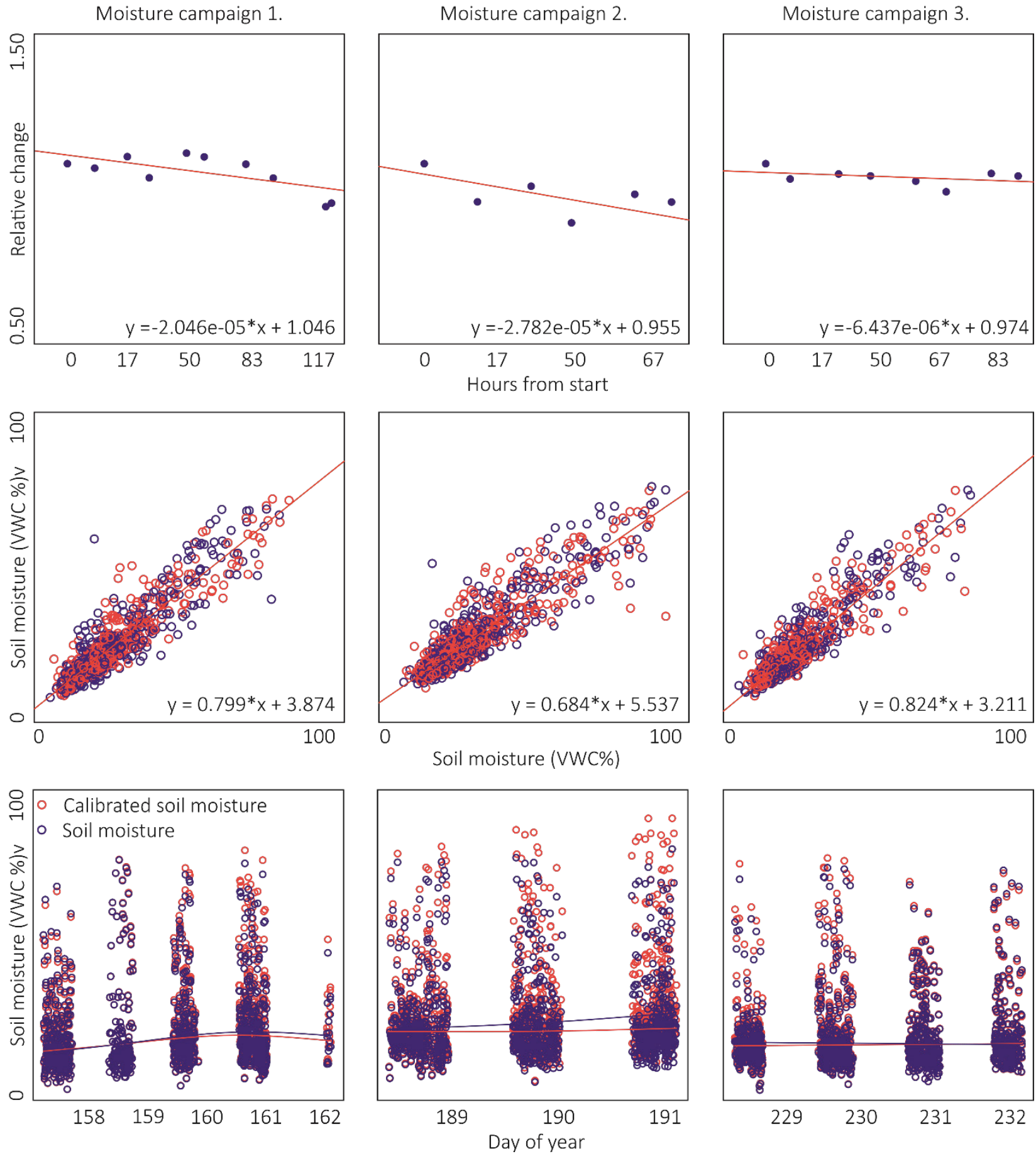

Observed and calibrated soil moisture observations. A calibration transect situated on a soil moisture gradient located on a topographically variating terrain was measured throughout all campaigns. Temporal change at the calibration transect was tested with ANOVA F-test, and was found statistically significant only for the first moisture campaign, yet the difference between observed and calibrated values was rather subtle, only $0.5 \mathrm{VWC} \%$ on the average. Thus, for consistency and comparability between campaigns, we decided to use uncalibrated moisture values for all analyses. This figure is available in colour at wileyonlinelibrary.com/journal/espl 


\section{Supplementary Material Appendix C}
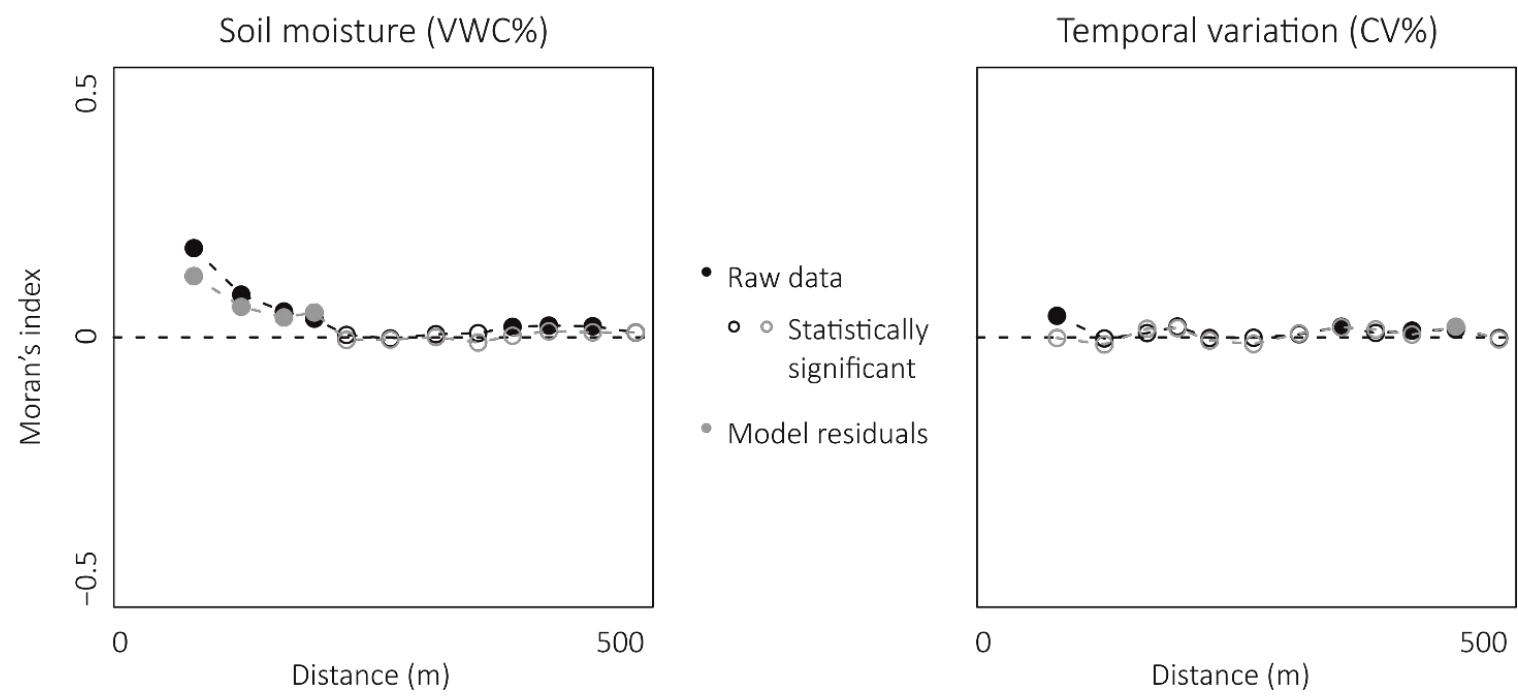

Spatial structure and spatial autocorrelation of soil moisture on all 1043 study plots used in the analyses. In the regard of soil moisture, plots close to each other $(<100 \mathrm{~m})$ had high spatial autocorrelation. In the regard of temporal variation of soil moisture, spatial autocorrelation was nearly absent. Thus, we did not continue into further evaluation of spatial autocorrelation. This figure is available in colour at wileyonlinelibrary.com/journal/espl 
A summary of response and predictor variables. Due to the nature of factor variables, surficial deposits are not represented in this table.

\begin{tabular}{rccc} 
& mean & sd & range \\
\hline Soil moisture $(\mathrm{VWC})$ & 22.0 & 12.5 & $4.6-78.2$ \\
Temporal variation $(\mathrm{CV} \%)$ & 25.0 & 14.4 & $1.3-99.0$ \\
Organic layer depth $(\mathrm{cm})$ & 6.3 & 6.9 & $0.0-70.0$ \\
Elevation $(\mathrm{m})$ & 667.6 & 53.7 & $582.3-807.5$ \\
Radiation $\left(\mathrm{kWh} / \mathrm{m}^{2}\right)$ & 433.8 & 51.9 & $257.7-555.9$ \\
$\mathrm{SWI}$ & 5.2 & 2.4 & $0.2-14.4$ \\
$\mathrm{TPI}$ & 0.0 & 0.8 & $-2.9-11.1$
\end{tabular}

Supplementary Material Appendix E

Comparing methods for modelling and predicting soil moisture and its temporal variation. Four statistical multivariate modelling methods commonly used in environmental research for analysing large data sets were evaluated for modelling soil moisture: generalized linear models (GLM), generalized additive models (GAM), boosted regression trees (BRT), and random forests (RF). In addition, an ensemble model (ENS based on all four modelling methods was evaluated.

\begin{tabular}{|c|c|c|c|c|c|c|c|c|c|c|c|c|c|c|c|c|c|c|}
\hline & \multicolumn{9}{|c|}{ Soil mo isture (UWC\%) } & \multicolumn{9}{|c|}{ Temporal variation ( $\mathrm{CV} \%$ ) } \\
\hline & \multicolumn{3}{|c|}{ mean } & \multicolumn{3}{|c|}{ so } & \multicolumn{3}{|c|}{ range } & \multicolumn{3}{|c|}{ mean } & \multicolumn{3}{|c|}{ sd } & \multicolumn{3}{|c|}{ range } \\
\hline & $R^{2}$ & RMSE & NSE & $R^{2}$ & RMSE & NSE & $R^{2}$ & RMSE & NSE & $R^{2}$ & RMSE & NSE & $R^{2}$ & RMSE & NSE & $R^{2}$ & RMSE & NSE \\
\hline & \multicolumn{18}{|c|}{ Model fit } \\
\hline GLM & 0.46 & 9.29 & 0.44 & 0.02 & 0.25 & 0.02 & 0.09 & 1.08 & 0.09 & 0.02 & 14.68 & -0.06 & 0.01 & 37 & 0.01 & 0.04 & .60 & 0.05 \\
\hline GAM & 0.49 & 9 & 47 & 0.02 & 0.25 & 0.02 & 0.10 & & 0.1 & 0.03 & 14. & -0.05 & 0.01 & 37 & 0.01 & 0.05 & 57 & 0.06 \\
\hline BRT & 0.57 & 8.83 & 0.50 & 0.02 & 0.23 & 0.02 & 0.08 & 1.12 & 0.0 & 0.06 & 14.70 & -0.06 & 0.01 & 0.37 & 0.01 & 0.09 & 1.56 & 0.06 \\
\hline RF & 0.90 & 4.98 & 0.84 & 0.00 & 0.15 & 0.01 & 0.02 & 0.71 & 0.0 & 0.88 & 8.45 & 0.65 & 0.01 & 0.27 & 0.01 & 0.04 & 1.12 & 0.05 \\
\hline ENS & 0.57 & 8.59 & 0.52 & 0.02 & 0.24 & 0.02 & 0.09 & 1.11 & 0.09 & 0.09 & 14.31 & -0.01 & 0.01 & 0.37 & 0.01 & 0.08 & 1.59 & 0.06 \\
\hline \multicolumn{19}{|c|}{ Predictive performance } \\
\hline GLM & 0.45 & 9.41 & 0.43 & 0.05 & 0.65 & 0.05 & 0.23 & 2.65 & 0.23 & 0.01 & 15.09 & -0.09 & 0.01 & 0.94 & 0.04 & 0.03 & 4.40 & 0.21 \\
\hline GAM & 0.47 & 9.24 & 0.45 & 0.04 & 0.65 & 0.04 & 0.24 & 2.96 & 0.20 & 0.01 & 15.33 & -0.13 & 0.01 & 1.59 & 0.26 & 0.04 & 13.80 & 2.44 \\
\hline BRT & 0.47 & 9.49 & 0.42 & 0.05 & 0.69 & 0.04 & 0.24 & 3.41 & 0.18 & 0.01 & 15.08 & -0.08 & 0.01 & 0.92 & 0.04 & 0.04 & 4.25 & 0.17 \\
\hline RF & 0.48 & 9.28 & 0.44 & 0.05 & 0.68 & 0.04 & 0.21 & 3.43 & 0.1 & 0.00 & 15.55 & -0.15 & 0.00 & 0.91 & 0.04 & 0.02 & 4.09 & 0.26 \\
\hline ENS & 0.48 & 9.26 & 0.44 & 0.05 & 0.67 & 0.04 & 0.25 & 3.15 & 0.19 & 0.01 & 15.09 & -0.09 & 0.01 & 0.93 & 0.04 & 0.04 & 4.36 & 0.19 \\
\hline
\end{tabular}

\begin{tabular}{|c|c|c|c|c|c|c|c|c|c|c|c|c|c|c|c|c|c|c|}
\hline & \multicolumn{6}{|c|}{ Soil moisture June } & \multicolumn{6}{|c|}{ Soil moisture July } & \multicolumn{6}{|c|}{ Soil moisture August } \\
\hline & \multicolumn{2}{|c|}{ mean } & \multicolumn{2}{|c|}{ so } & \multicolumn{2}{|c|}{ range } & \multicolumn{2}{|c|}{ mean } & \multicolumn{2}{|c|}{ so } & \multicolumn{2}{|c|}{ range } & \multicolumn{2}{|c|}{ mean } & \multicolumn{2}{|c|}{ sd } & \multicolumn{2}{|c|}{ range } \\
\hline & $R^{2}$ & RMSE & $R^{2}$ & RMSE & $R^{2}$ & RMSE & $R^{2}$ & RMSE & $R^{2}$ & RMSE & $R^{2}$ & RMSE & $R^{2}$ & RMSE & $R^{2}$ & RMSE & $R^{2}$ & RMSE \\
\hline & \multicolumn{18}{|c|}{ Model fit } \\
\hline GLM & 0.46 & 10.59 & 0.02 & 0.26 & 0.12 & 1.25 & 0.39 & 11.19 & 0.02 & 0.27 & 0.11 & 1.40 & 0.33 & 10.19 & 0.02 & 0.31 & 0.10 & 1.65 \\
\hline GAM & 0.48 & 10.40 & 0.02 & 0.28 & 0.12 & 1.39 & 0.43 & 10.92 & 0.02 & 0.27 & 0.09 & 1.33 & 0.36 & 10.00 & 0.02 & 0.32 & 0.10 & 1.66 \\
\hline BRT & 0.55 & 10.32 & 0.02 & 0.26 & 0.09 & 1.23 & 0.51 & 10.61 & 0.02 & 0.30 & 0.10 & 1.52 & 0.44 & 9.83 & 0.02 & 0.34 & 0.11 & 1.74 \\
\hline RF & 0.90 & 5.75 & 0.01 & 0.20 & 0.03 & 0.89 & 0.90 & 5.95 & 0.01 & 0.19 & 0.03 & 0.94 & 0.88 & 5.79 & 0.01 & 0.22 & 0.03 & 1.05 \\
\hline ENS & 0.56 & 9.87 & 0.02 & 0.26 & 0.11 & 1.29 & 0.51 & 10.37 & 0.02 & 0.28 & 0.09 & 1.40 & 0.45 & 9.63 & 0.02 & 0.32 & 0.10 & 1.66 \\
\hline \multicolumn{19}{|c|}{ Predictive performance } \\
\hline GLM & 0.44 & 10.70 & 0.06 & 0.68 & 0.29 & 3.41 & 0.38 & 11.28 & 0.05 & 0.72 & 0.24 & 3.41 & 0.33 & 10.10 & 0.05 & 0.81 & 0.26 & 4.07 \\
\hline GAM & 0.45 & 10.60 & 0.06 & 0.72 & 0.29 & 3.60 & 0.40 & 11.05 & 0.05 & 0.73 & 0.22 & 3.18 & 0.35 & 9.98 & 0.05 & 0.84 & 0.21 & 3.75 \\
\hline BRT & 0.45 & 10.96 & 0.05 & 0.73 & 0.25 & 3.85 & 0.41 & 11.22 & 0.05 & 0.78 & 0.25 & 3.40 & 0.34 & 10.22 & 0.05 & 0.87 & 0.24 & 3.60 \\
\hline RF & 0.46 & 10.63 & 0.05 & 0.72 & 0.25 & 3.53 & 0.40 & 11.09 & 0.05 & 0.77 & 0.26 & 3.12 & 0.33 & 10.10 & 0.05 & 0.87 & 0.23 & 3.63 \\
\hline ENS & 0.47 & 10.60 & 0.05 & 0.70 & 0.26 & 3.69 & 0.42 & 11.05 & 0.05 & 0.75 & 0.23 & 3.21 & 0.35 & 10.03 & 0.05 & 0.85 & 0.22 & 3.68 \\
\hline
\end{tabular}


Supplementary Material Appendix F

Relationships between variables. Spearman correlations was used to calculate the correlations between numerical variables, and polyserial correlation used for the factor variable (surficial elements) and other predictor variables. Statistical significance of the correlation: ${ }^{* *}=p \leq 0.001 ;{ }^{* *}=p \leq 0.01$; ${ }^{*}=p \leq 0.05$; ns $=$ not significant.

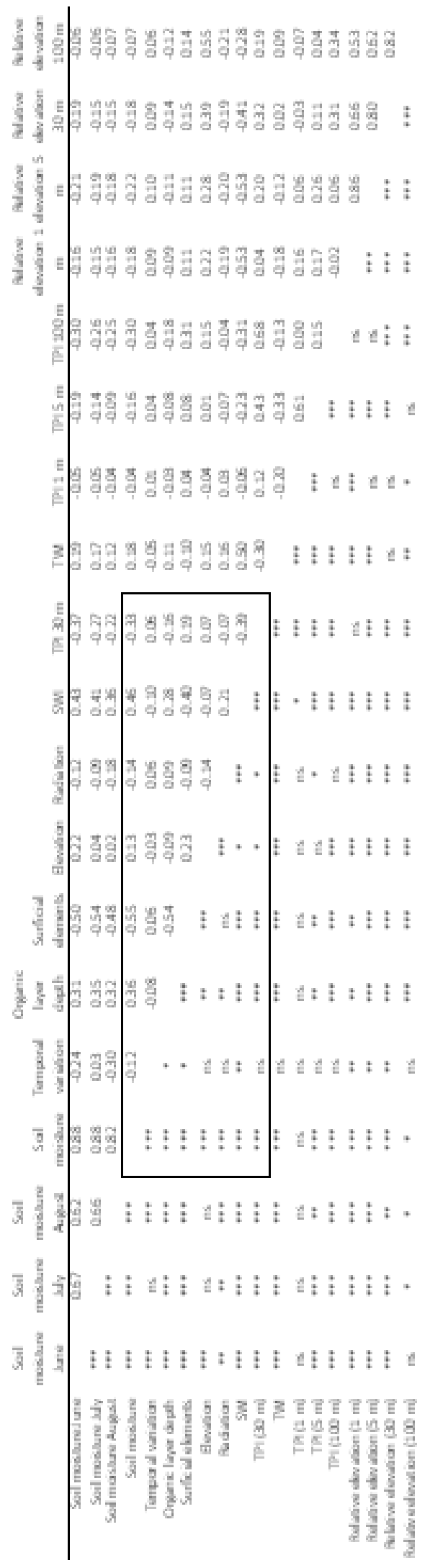




\section{Supplementary Material Appendix G}

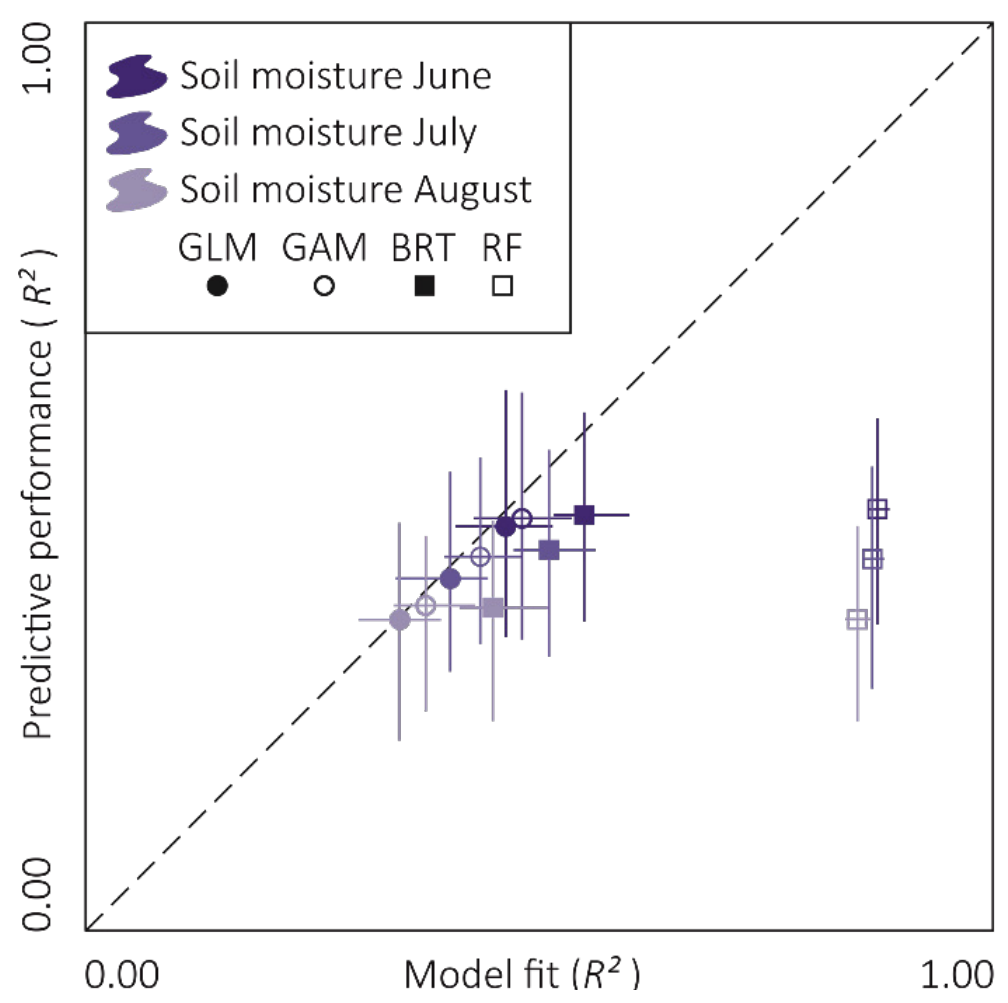

Comparing four soil moisture modelling methods and three soil moisture campaigns. The horizontal and vertical segments represent the ranges of each modellingmethod, which insomecaseswereveryminor,e.g., RFfortemporalvariation. Thisfigure isavailable incolouratwileyonlinelibrary.com/journal/espl 


\section{Supplementary Material Appendix $\mathrm{H}$}
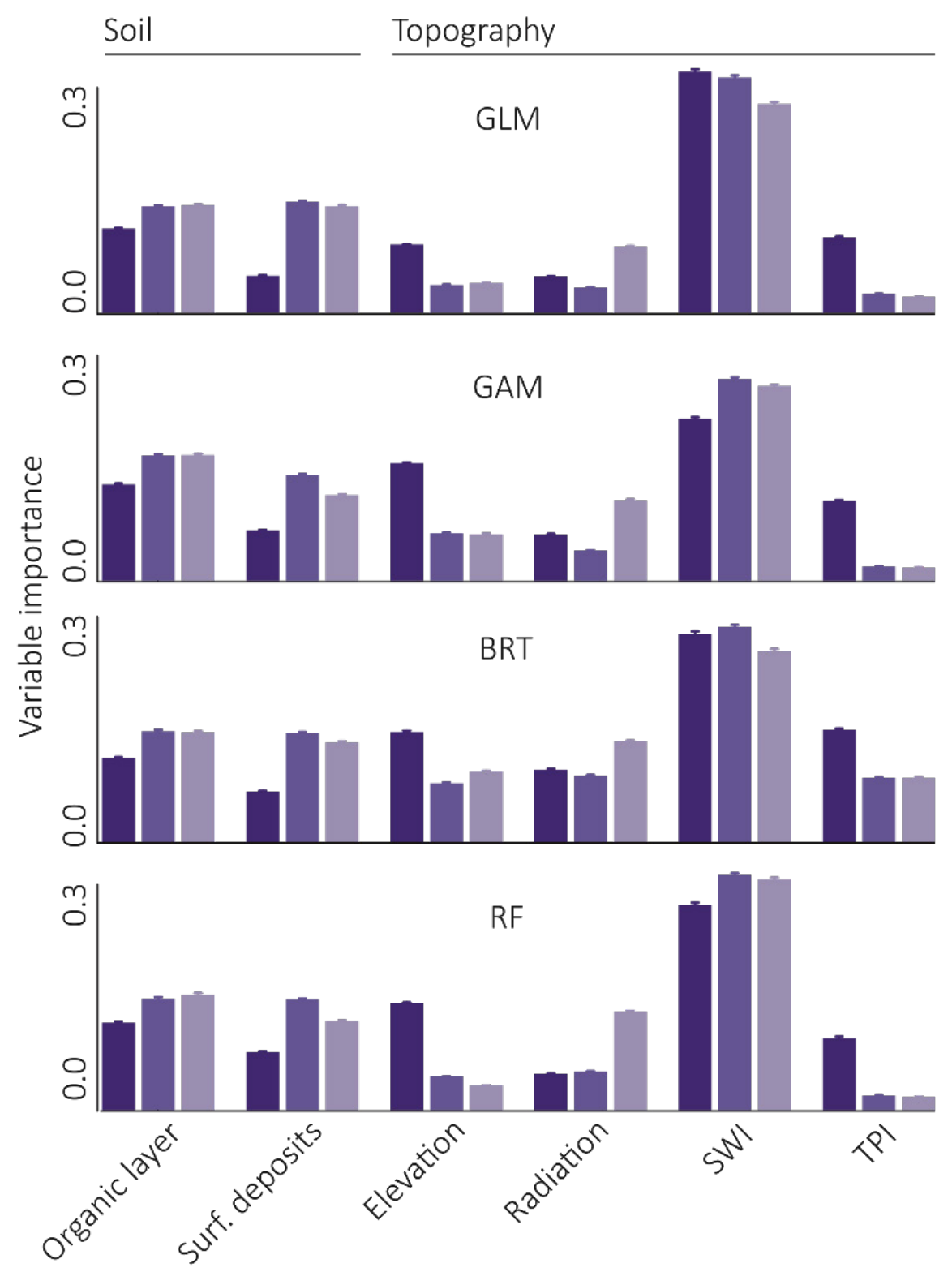

Soil moisture June

Soil moisture July

Soil moisture August

Variable importance. All modelling methods and campaigns indicated soil moisture to be influenced mainly by SWI, with additional important effects from soil properties. Error bars show the confidence interval of $95 \%$. This figure is available in colour at wileyonlinelibrary.com/journal/espl 


\section{Supplementary Material Appendix I}

A) Soil moisture June

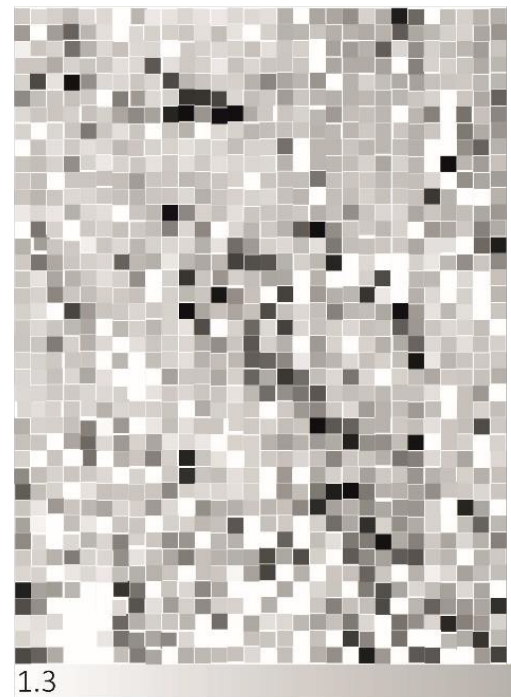

D) Soil moisture (VWC\%)

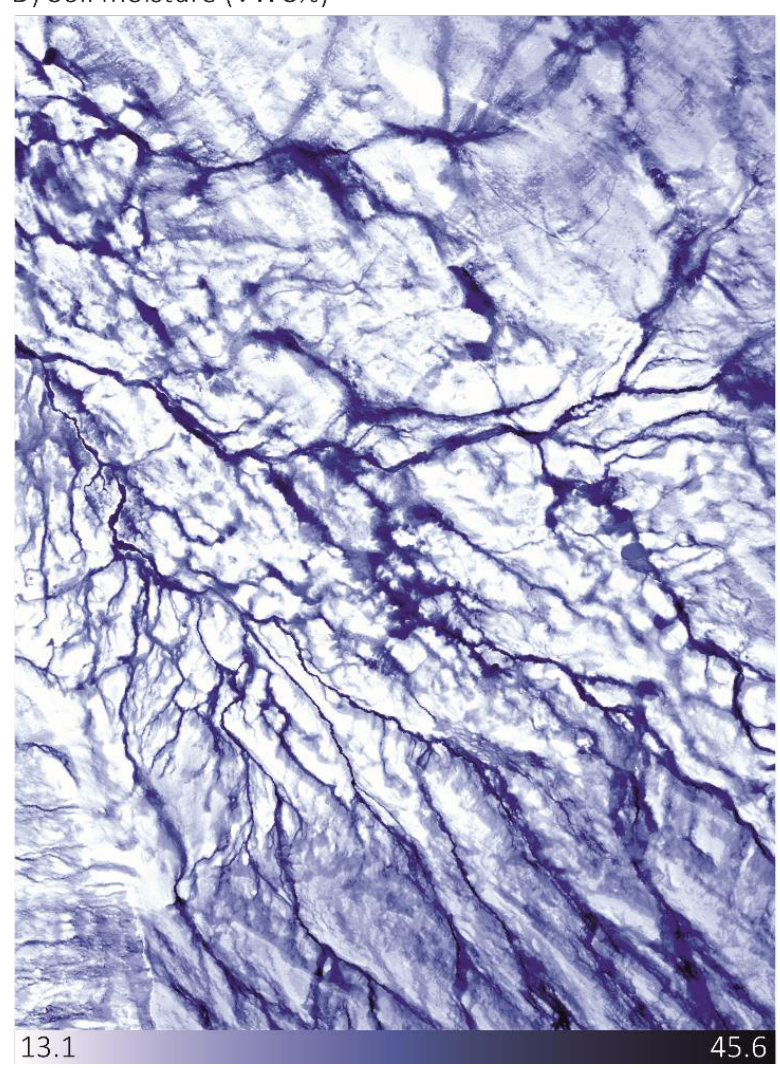

B) Soil moisture July

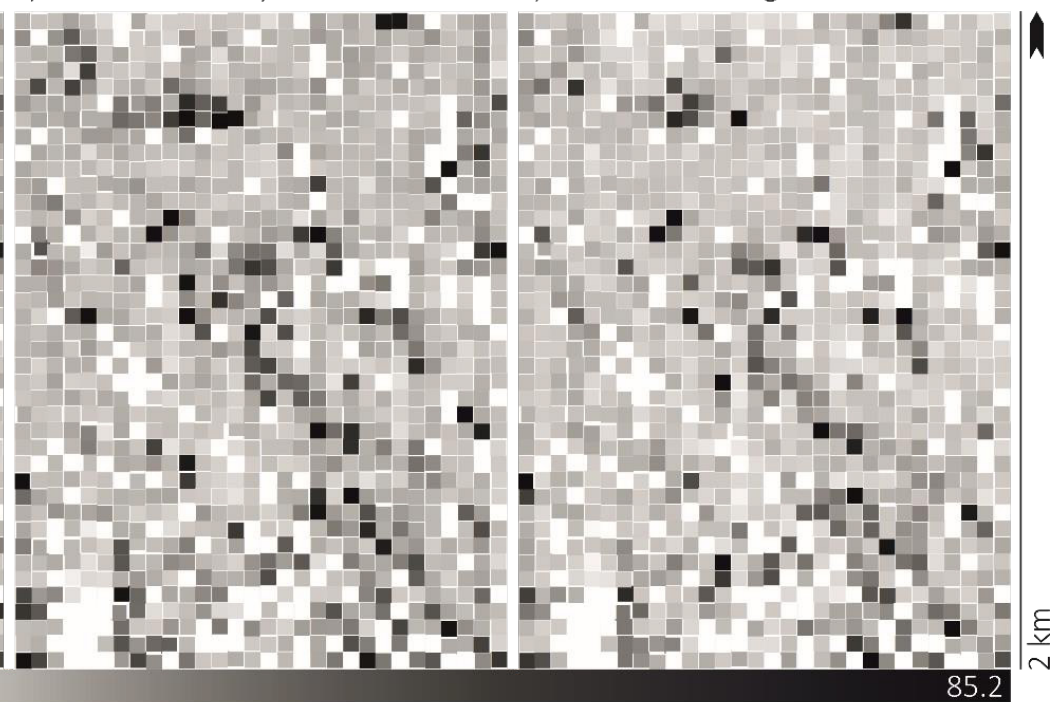

E) Temporal variation (CV\%)

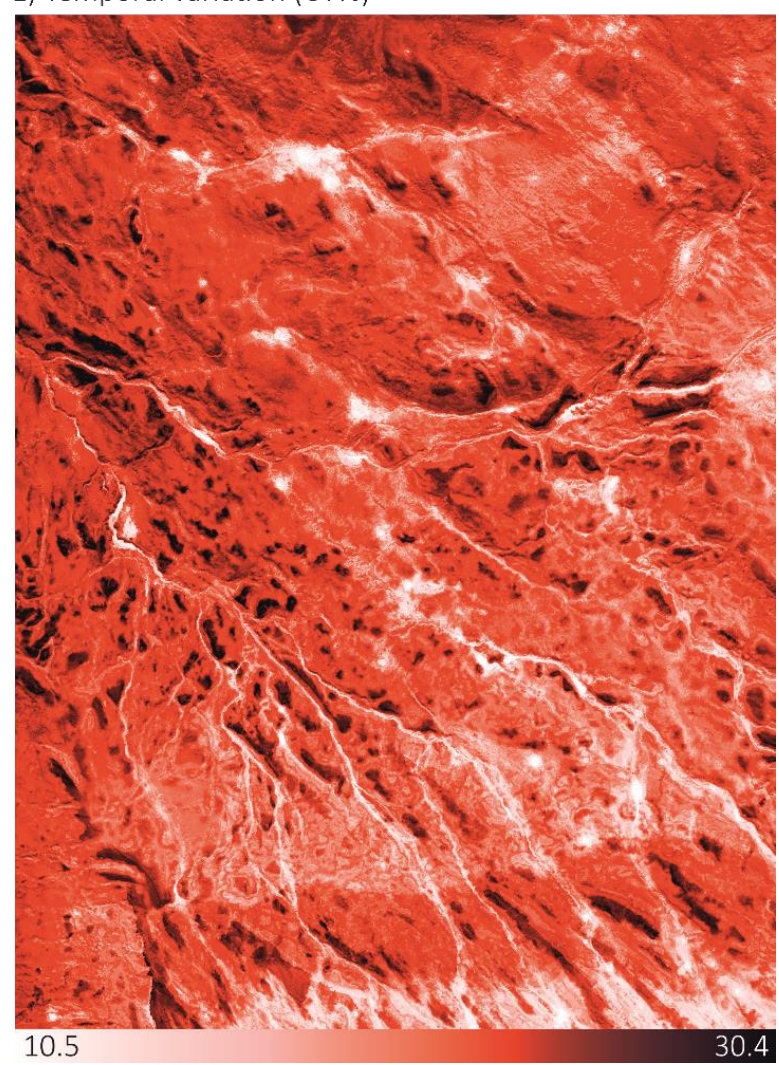

Spatial variation of soil moisture and its temporal variation, observed $(A-C)$ and predicted $(D-E)$. Predictions were based on the 1200 plots, from which soil moisture was investigated during three moisture campaigns $(A-C)$. The blank spaces represent the remaining 157 plots, from which measurements were not possible to obtain. Soil moisture (D) and its temporal variation (E) predictions are based on the mean of the three measurements and the coefficient of variation (CV) (Equation 1). This figure is available in colour at wileyonlinelibrary.com/journal/espl 